Check for updates

Cite this: Mater. Adv., 2021, 2, 4479

Received 19th March 2021 Accepted 3rd June 2021

DOI: 10.1039/d1ma00240f

rsc.li/materials-advances

\title{
Magnetic nanoparticles: an emerging nano-based tool to fight against viral infections
}

\author{
Sanjeev K. Jat, (D) $\dagger^{\mathrm{a}}$ Harsh A. Gandhi, $\dagger^{\mathrm{b}}$ Jaydeep Bhattacharya (D) $*^{\mathrm{b}}$ and \\ Manoj K. Sharma (D)*a
}

\begin{abstract}
Viral infections have threatened public health for a long time and have severely impacted socioeconomic development. Traditional diagnostic and therapeutic methods are not enough to control the viral contagions that have been realized by numerous pandemics. Thus, it is necessary to develop novel diagnostic methods, as well as therapeutic strategies against the existing and emerging viruses. The advent of nanotechnology has enabled us to think differentially about the management of viral diseases. Magnetic nanoparticles (MNPs) are a class of nanomaterials that have extensively been used in different biological applications. They have also shown their potential as active antimicrobial agents against several bacteria, viruses, and other microorganisms. Here, we would like to apprise the scientific community about the use of MNPs as a novel tool for viral diagnostics and antiviral applications. This review summarizes the advances in the clinical diagnosis, detection, and therapeutic applications of magnetic nanoparticles against viral infections.
\end{abstract}

\section{Introduction}

Infectious diseases caused by viruses, bacteria, fungi, and parasites have instigated millions of fatalities worldwide. ${ }^{1}$ In recent decades, changes in the pattern of infectious disease

${ }^{a}$ Crop Genetics \& Informatics Groups, School of Biotechnology, Jawaharlal Nehru University, New Delhi 110067, India. E-mail: mksharma@jnu.ac.in

${ }^{b}$ Nanobiotechnology Laboratory, School of Biotechnology, Jawaharlal Nehru University, New Delhi 110067, India. E-mail: jaydpb@gmail.com

$\dagger$ These authors contributed equally to this work.

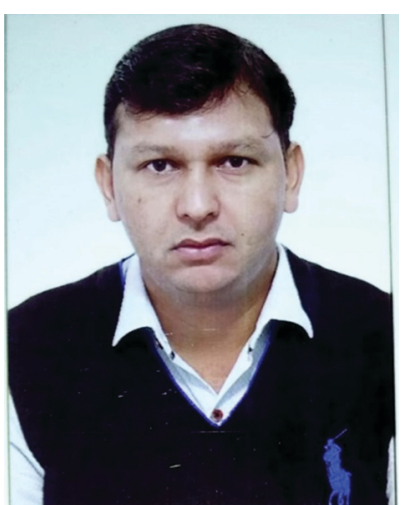

Sanjeev K. Jat
Sanjeev K. Jat is currently working as a national postdoctoral fellow under the supervision of Dr Manoj K. Sharma at Crop Genetics \& Informatics Groups, School of Biotechnology, Jawaharlal Nehru University, New Delhi, India. He received his $P h D$ from Anna University Chennai, in 2019. His research interests include nanoparticle synthesis, controlled drug release, hyperthermia action, and biomolecule delivery, especially nanoparticle-based gene delivery to plant/mammalian hosts. spread such as the emergence of new diseases, re-emergence of the controlled diseases, expansion of existing pathogens to new geographic regions, increasing mortality rates, and the development of antimicrobial resistance are of special concern. ${ }^{2,3}$ Human activities, such as changing lifestyles, ${ }^{4}$ increasing pollution, ${ }^{5}$ population growth, ${ }^{6}$ poverty and malnutrition, ${ }^{6}$ increasing contact with wild animals, ${ }^{7}$ extensive international travel, ${ }^{8}$ poor health care resources, and rapidly changing global landscapes and local environments, have played a huge role in this expansion and emergence of infectious diseases. ${ }^{5,9}$ Communicable diseases caused by viruses are among the

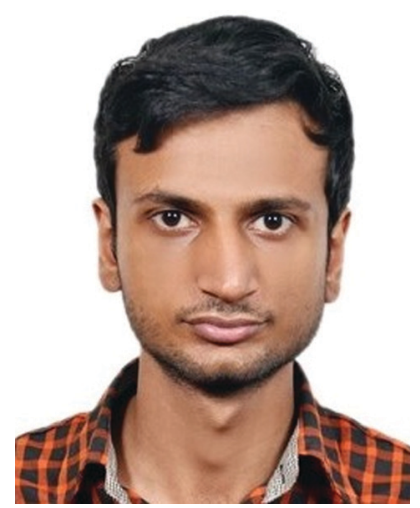

Harsh A. Gandhi
Harsh A. Gandhi is a research fellow under the supervision of Dr Jaydeep Bhattacharya at Nanobiotechnology Laboratory, School of Biotechnology, Jawaharlal Nehru University, New Delhi, India. He received his MSc from the School of Biotechnology, Jawaharlal Nehru University, New Delhi, in 2019. His research interests include nanoparticles synthesis, targeted biomolecule delivery, kinetic studies of the interactions of nanoparticles with biomolecules, the development of biosensors, and lab-on-a-chip development. 
leading causes of large-scale health disasters affecting millions of people worldwide along with a deleterious impact on health, social and economic developments. ${ }^{10,11}$ The unique ability of rapid mutation enables the viruses to adjust to their present host, switch to a new host, or develop strategies to escape antiviral measures, and are major challenges to controlling the viral infections. ${ }^{11,12}$ It is reported that most of the emerging human viral pathogens are generally zoonotic in origin and two-thirds of them have originated in wildlife. ${ }^{13,14}$ However, wild animal-borne, arboviral, or respiratory viral infections have been the main causes of most epidemics or pandemics since the 19th century. ${ }^{11,15}$ Pandemic influenza (H1N1), ${ }^{16}$ highly pathogenic avian influenza infection (H5N1), ${ }^{17}$ the middle east respiratory syndrome coronaviruses (MERS-CoV), ${ }^{18}$ Ebola, ${ }^{11}$ $\mathrm{Zika}^{19}$ SARS (severe acute respiratory syndrome) coronavirus, ${ }^{11,20}$ west Nile virus, ${ }^{21}$ monkeypox virus, ${ }^{22}$ hantavirus, ${ }^{23}$ Nipah virus ${ }^{24}$ and, most recently, SARS-CoV-02, ${ }^{25}$ are a few examples of viral diseases that have had a huge impact on human health and socio-economic status. ${ }^{11,26}$ Other viruses like hepatitis viruses (mainly $\mathrm{HBV}$ and $\mathrm{HDV}$ ), ${ }^{27}$ human immunodeficiency virus (HIV) ${ }^{28}$ and influenza virus also cause considerable distress in the human population. ${ }^{29}$

Generally, virus replication is directed by complex molecular interactions between the virus and host cell machinery, and the virus uses the host cell machinery for the synthesis and assembly of various viral components. ${ }^{30}$ Viruses bind and release their genome in the host cell, where it is transcribed and viral proteins are synthesized in a well-controlled manner. ${ }^{30,31}$ Subsequently, the virus undergoes multiple genome replications and new virion particles are assembled, which are then released from the cell. ${ }^{12,30}$ Therefore, the steps of the viral life cycle along with viral antigens and antibodies generated in the host against viruses can be the possible targets for the diagnosis, detection, and inhibition of viral infections. ${ }^{32,33}$ There are several commonly used diagnostic methods for the clinical diagnosis and detection of viral infections such as antibody/antigen tests or nucleic acid amplification methods. ${ }^{32,33}$ The viral antigen/antibody detection method includes enzyme immunoassay (EIA), fluorescent antibody (FA) staining, and immune-peroxidase staining. ${ }^{32}$ On the other hand, the viral nucleic acid can potentially be detected using PCR (polymerase chain reaction) techniques. ${ }^{34}$ Molecular diagnostic methods have revolutionized diagnostic virology, however, higher rates of falsepositive and false-negative results are still a major challenge for the precise diagnosis of viral infections.

In order to control the viral spread, vaccination is one of the most widely used methods, and vaccines against several viral pathogens like smallpox, H1N1, hepatitis, polio, measles, etc., have been developed. ${ }^{35}$ Although viral diseases like smallpox and polio have been successfully controlled by vaccination, the design and synthesis of a vaccine is a time-consuming and laborious process. ${ }^{36,37}$ Moreover, the higher mutation rate of the viruses also makes the task more difficult, leading to the continuous re-development of vaccines. Besides vaccines, there are several antiviral drugs such as acyclovir, atazanavir, raltegravir, etc., which are available on the market for the control and treatment of multiple virus illnesses like influenza, HIV, and hepatitis $\mathrm{C}$ infections. ${ }^{38}$ However, there are still many viral pathogens for which vaccines or drugs are not available. ${ }^{36}$ Many of these infections can be highly contagious and in the absence of vaccines or antiviral drugs, it is a major challenge to control their spread. Therefore, new antiviral agents or therapy are highly needed against viruses of different families for clinical management.

To overcome the limitations, the scientific community is exploring novel ways to control or eradicate viral pathogens and in such a scenario, nanotechnology can play an important role in the design and synthesis of nanoparticles-based antiviral agents. Nanotechnology provides the opportunity to develop various nanoscale materials with desired properties by controlling their size, shape, and surface area. Nanomaterials are already being used in biomedical research as novel therapeutical agents,

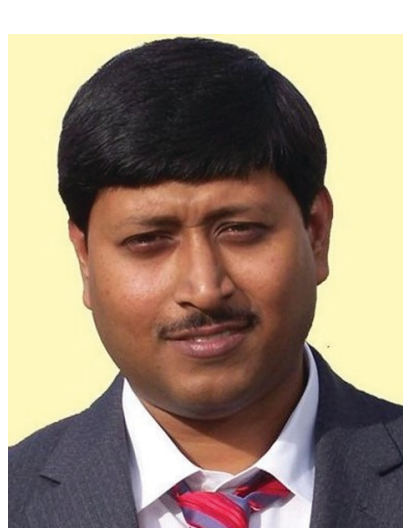

Jaydeep Bhattacharya
Jaydeep Bhattacharya has been working in the field of nanobiotechnology for the last 17 years. He is currently an Assistant Professor at the School of Biotechnology, JNU, New Delhi. His research interests include the synthesis of different metal, metal oxide, and polymerbased nanomaterials and their use in different biological and biomedical applications. He also works in the field of microfluidics device fabrication and the development of biosensors.

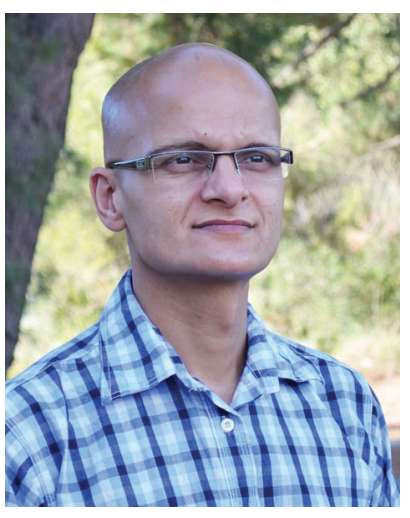

Manoj K. Sharma
For more than 15 years, Dr Sharma has been conducting plant genetic/ genomic engineering and development of tools for functional genomic studies in plants. Currently, he is an Assistant Professor, at the School of Biotechnology, Jawaharlal Nehru University, New Delhi. He has extensive expertise in the area of plant genomics and genetic engineering, stress biology, and major focus of his research group is the development of nanotechnology-mediated functional genomics tools for recalcitrant crops. 


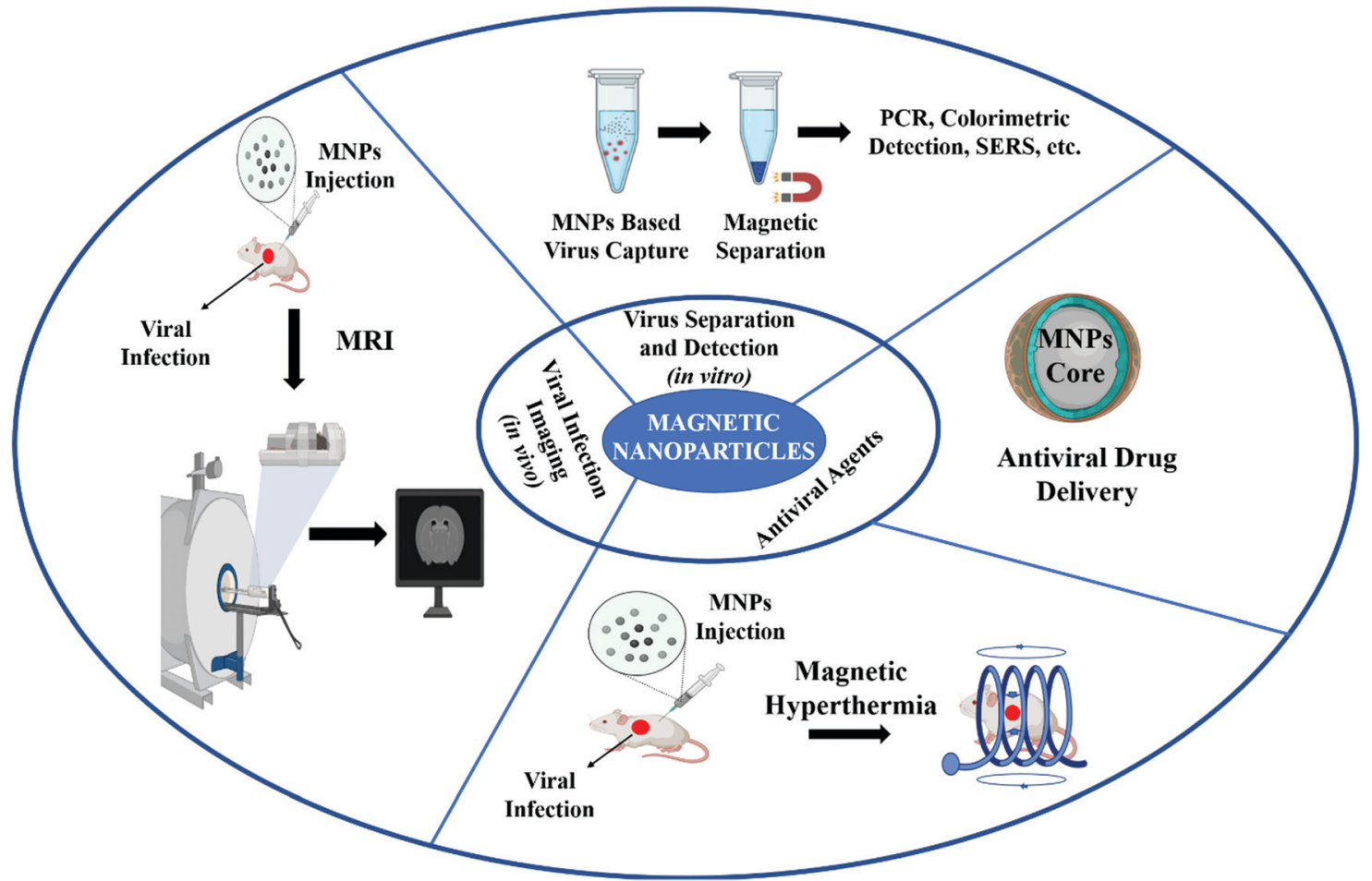

Fig. 1 Schematic representation of the various applications of MNPs in virology

drug carriers, pathogen detections, and/or biomolecular sensors. ${ }^{39,40}$ Distinctive physicochemical properties of nanomaterials, such as small particle size, high surface area to volume ratios, and surface charge, are advantageous since these properties help to increase the drug load and deliver the drug cargo to the desired site as well as help in cellular entry across the cellular membrane. ${ }^{41,42}$ Such distinct features of nanoparticles have made them a vital tool against viral infections. Significant advances have been made in the use of nanoparticles for the diagnosis and detection of various viral pathogens, as well as the development of nanoparticle-based antiviral agents. ${ }^{43,44}$ Various engineered nanobased materials such as silver/gold NPs, carbon quantum dots, dendrimers, or magnetic nanoparticles, which contain biomimetic properties, have been developed for the diagnosis, detection, and treatment of viral infections. ${ }^{45}$

Magnetic nanoparticles (MNPs) provide several advantages and possess great promise in the treatment and diagnosis of viral infections. MNPs is a general term that includes various nanostructures composed of different elements like cobalt, iron, platinum, nickel, etc., or metal alloys and bimetallic NPs. ${ }^{46}$ However, iron element, in the form of either maghemite $\left(\mathrm{Fe}_{2} \mathrm{O}_{3}, \gamma-\mathrm{Fe}_{2} \mathrm{O}_{3}\right)$ or magnetite $\left(\mathrm{Fe}_{3} \mathrm{O}_{4}\right)$, has been used more frequently because of its wide potential in biomedicine. ${ }^{47}$ MNPs are not only being used in the field of medical research, ${ }^{48}$ clinical diagnosis, magnetic resonance imaging, ${ }^{49}$ labeling, drug delivery ${ }^{50}$ and hyperthermia, ${ }^{51}$ but are also being used for the development of electrochemical, optical, piezoelectric, and magnetic field sensors. ${ }^{52}$ Recently, iron oxide MNPs have been successfully used for the treatment and prevention of $\mathrm{H} 1 \mathrm{~N} 1$ viral infections. ${ }^{53}$ Here, we discuss the intrinsic magnetic properties of the MNPs and various strategies or tools that can be used for the isolation, detection, and clinical diagnosis of viral infections. We also review the recent developments of MNP applications for the treatment of viral infections, opportunities, perspective merits, as well as the challenges ahead. Fig. 1 shows the general applications of MNPs in clinical diagnosis, the detection and control of viral infections.

\section{A. Magnetic nanoparticles: their roles in the isolation, detection, and clinical diagnosis of viral particles}

Diagnostic tests typically make it possible to recognize the microorganism that induces an infectious disorder and they are used to conduct susceptibility testing to recommend the most effective treatment. ${ }^{54}$ The medical, social, and economic advantages of diagnostic tests have helped to enhance patient care, as well as to minimize health issues. ${ }^{55}$ Depending on the identification targets, viral diagnostic testing can usually be divided into two categories: the direct detection of the virus through viral nucleic acids by the reverse transcriptionpolymerase chain reaction (RT-PCR/PCR) and proteins through sodium dodecyl sulfate-polyacrylamide gel electrophoresis (SDS-PAGE), or indirect detection using antibodies produced as an immune response against viral infection in the host by the method of the enzyme-linked immunosorbent assay (ELISA), radioimmunoassay (RIA), etc. ${ }^{56}$ However, these traditional methods are time-consuming, require high-end equipment and hence are expensive. ${ }^{56}$ Therefore, to reduce the time and the associated cost, diverse types of nanomaterials have been developed to detect and quantify the viral load. Biological materials, in 


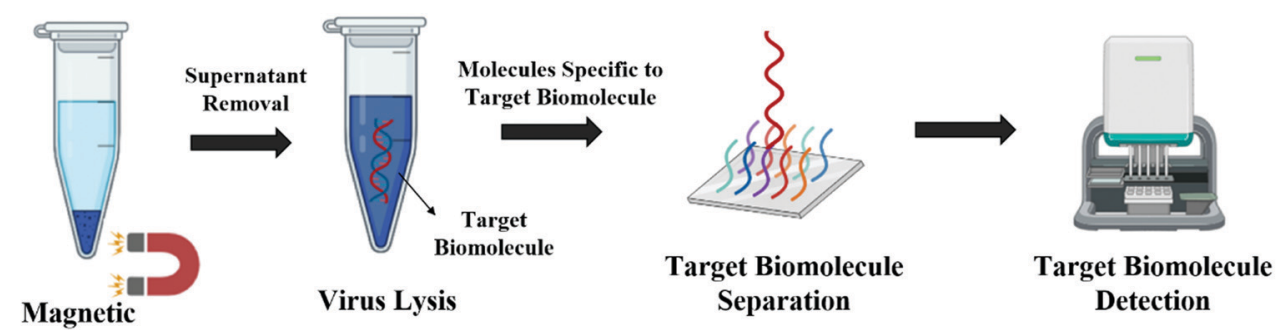

Separation

MNPs Based Virus Isolation and Detection

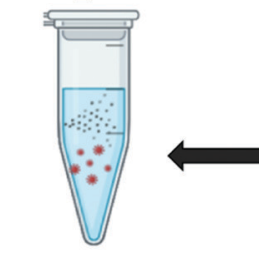

MNPs Based Virus Capture

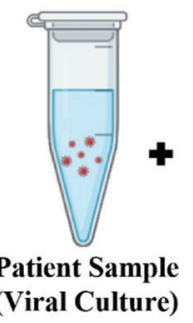

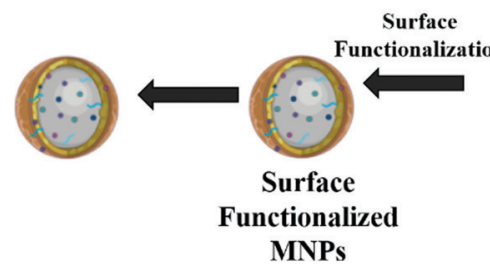

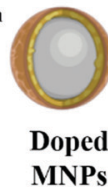

Doped
MNPs

MNPs

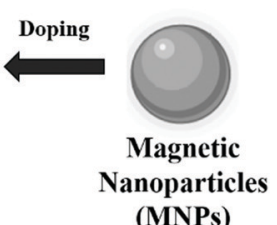

(MNPs)

Fig. 2 Schematic representation of MNPs-based virus detection.

general, lack intrinsic magnetic properties, and therefore, MNPs have an edge over other nanomaterials, which can be used to detect specific biomolecules without affecting the biological systems. Iron oxide nanoparticles are among the most widely used MNPs in biomedical research and have been successfully used for the clinical diagnosis of several pathogens. ${ }^{57}$ In general, MNPs are labeled with oligonucleotides, antibodies, or specific viral binding proteins that can hybridize to the specific viral target. ${ }^{58}$ Fig. 2 shows a schematic representation of the magnetic nanoparticlesbased isolation and detection of viruses.

Some of the commonly used MNP-based viral detection methods include magnetic resonance imaging/nuclear magnetic resonance-based (MRI/NMR) detection, real-time/quantitative reverse transcription-polymerase chain reaction (rRT PCR/ qPCR)-based detection of nucleic acid, sodium dodecyl sulfate polyacrylamide gel electrophoresis (SDS-PAGE), and mass spectrometry-based detection of viral protein, enzyme-linked immune sorbent assay (ELISA)-based detection of antibody binding against the viral antigen, and localized surface plasmon resonance/surface-enhanced Raman spectroscopy-based detection (LSPR/SERS), which are discussed in the following sections.

1. MRI/NMR-based detection. The non-invasive examination and imaging of the internal organs of the human body have long been a challenge for physicians and researchers. Magnetic resonance imaging (MRI) is the most common diagnostic imaging modality in clinical medicine owing to its excellent spatial resolution, non-invasive and non-destructive nature.$^{59} \mathrm{MRI}$ is a procedure for imaging soft tissue but in some cases, adequate contrast formation for the differentiation of various tissue types (healthy and deceased) becomes a challenge. Contrasting agents (CAs) like gadolinium, manganese, etc., are being used for signal enhancement to improve the image quality. ${ }^{49}$ However, these contrasting agents may have a negative or toxic effect on the biological system. ${ }^{49,59}$ Nanotechnology has revolutionized the premise of the MRI imaging modality where different nanoparticles have shown potential in the field of medical imaging for their ability to act as specific CAs in vitro and in vivo. The combination of multimodal imaging and theranostics can lead to cutting-edge technology in which the potential of NPs can be maximized. MNPs are emerging as one of the most exciting probes to enhance contrast, not only at a cellular level but also at the molecular level. ${ }^{49,60}$ Iron element has widely been used to synthesize contrast agents in various forms like metals, oxides, or ferrites, where other elements like $\mathrm{Zn}$, or Gd can be introduced to change the magnetic moment and their surface functionalization. The use of MNPs in MRI enables a more effective diagnosis by increasing the contrast between tissues. Recently, MNPs have also been conjugated with targetdirecting molecules for the simulation of complex tissues and molecules.

Remarkably, most MRI MNP-based antigen detection methods focus on changes in the signals of the water molecules, which occur upon the interaction of MNPs with the target tissue, resulting in the clustering of MNPs. Further, the clustering of MNPs leads to changes in the microenvironment of water, which ultimately deviates the signal. Changes in these signals can be quantified using traditional MRI or NMR. ${ }^{61}$ MNPs in such scenarios mainly interact with antigens, antibiotics, or other biological targets to improve the signal sensitivity and spatial resolution, which can be later visualized by MRI or NMR and help in the detection of viral particles ${ }^{61}$ In particular, such devices are becoming increasingly convenient to work with (i.e., a benchtop format) and are highly sensitive.

Wang and coworkers demonstrated the NMR technique based on MNPs, which was able to detect protein levels below the detection limits of traditional ELISA of $10 \mathrm{pg} \mathrm{mL}{ }^{-1}{ }^{62}$ Shao and colleagues also developed various chip-based NMR 
detection techniques such as superconducting quantum interference device (SQUID), diagnostic magnetic resonance (DMR), magneto-resistive sensors, etc., which are capable of analyzing several microliter volumes of samples. These techniques have enabled parallel and rapid measurements from small volumes for a wide range of cells, proteins, mRNA, DNA, etc. ${ }^{58}$ Shen and his colleagues, on the other hand, established a histidine tag-based effective encapsulation of MNPs in viral-like particles (VLPs) and demonstrated that their cellular uptake efficiency and relaxivity were significantly higher than that of pure $\mathrm{Fe}_{3} \mathrm{O}_{4}$ nanoparticles. Further, these VLPs were demonstrated to increase contrast and minimize the relaxation time of water inside cells. The study highlights that uniformly sized, monodispersed MNPs posters with good biocompatibility and higher cellular uptake efficiency, can be good contrasting agents for MR imaging applications. ${ }^{58,63}$

Manuel Perez and colleagues (2003) have used the unique magnetic phenomenon that results from the self-assembly of MNPs and alters the relaxation time of the surrounding water molecules. These phenomena were used by the authors to create a magnetic nano-sensor that could detect viral particles in biological media. ${ }^{54}$ Shelby and group (2017) have also developed a magnetic relaxation technology that allows the rapid and sensitive analysis of simple host-pathogen interactions. ${ }^{64}$ Herein, magnetic relaxation-sensitive nanoparticles (MRNPs) were synthesized to analyze binding associations between the Zika envelope protein (ZENV) and proposed host cell receptors: AXL, HSP70, and TIM-1.

2. rRT PCR/qPCR-based detection of nucleic acid. Reverse transcription-polymerase chain reaction (rRT-PCR)-based molecular diagnostic techniques have been extensively used for the clinical diagnosis of various pathogens. However, laborintensive and time-consuming operations are still a huge challenge associated with PCR. The extraction of nucleic acids from the patient samples is one of the major issues in PCRbased techniques. ${ }^{65}$ Therefore, to address the issue, many research groups have extensively used silica-modified MNPs in the course of nucleic acid extraction and carboxyl-coated MNPs during the fluorescence detection step, which helps to modify the system for high-throughput applications, detecting even trace amounts of viral DNA/mRNA. ${ }^{66,67}$ PCR amplification of nucleic acid-based methods can be multiplexed and hence can be useful for the detection of multiple pathogens at the same time. The ability to multiplex also reduces the cost associated with disease diagnosis. ${ }^{68}$ However, these assays are not reliably consistent to detect a large number of pathogens at once. ${ }^{69}$

Chao and colleagues developed magnetic nano-trap hydrogelbased nanoparticles to extract and enrich the various viral particles. The group has successfully used these magnetic nano-traps to enrich the Zika virus, chikungunya virus, and dengue viruses. ${ }^{70}$ In this case, these viral particles were lysed and nucleic acids were isolated, which were further clinically detected by using rRT PCR. Zeeshan Ali and colleagues, on the other hand, have developed a single-step DNA hybridization process based on chemiluminescence to simultaneously detect many pathogens. ${ }^{71}$ Authors successfully used this method to detect hepatitis B virus (HBV), hepatitis C virus (HCV), and human immunodeficiency virus (HIV-1 group $\mathrm{M}$, herein referred to as HIV) in a multiplex detection protocol where multiplex RT-PCR reactions were performed. The detection sensitivity of the multiplex system in the presence of higher loads of various viruses was similar to the efficiency when these were detected in the monoplex system, and viral particles having the concentration of 10 viral copies per microliter of the serum could be detected. A similar kind of MNPs-based detection technique has also been developed by Michalek and colleagues (2016), where $\gamma-\mathrm{Fe}_{2} \mathrm{O}_{3}$ MNPs were used for the isolation of H7N7 virions, and detection was done using rRT PCR. ${ }^{72}$ However, PCR-based multiplexed detection systems may suffer from preferential amplification of the loci from one pathogen as compared to other pathogens and therefore, should be optimized carefully in all the combinations of target pathogens for any bias in amplification.

Recently, an MNPs-dependent extraction method for SARSCoV-2 viral RNA was reported by Zhao and colleagues (2020). ${ }^{73}$ Here, the group synthesized iron oxide nanoparticles coated with poly(amino ester) with carboxyl groups (pcMNPs), and later it was used for efficient RNA extraction. The method combines the lysis and binding steps during the RNA extraction, and can be used for PCR-based amplification and identification directly by MNP-RNA complexes. pcMNPs have very high dispersity in the water and therefore, pcMNP-RNA complexes can directly be used for PCR as the attached RNA is not shielded. Therefore, it allows primer binding and the synthesis of a complementary strand. Since precipitation and centrifugation of the nucleic acids are not required during the extraction procedure, a complete extraction protocol was successfully automated for multiple samples through a high-throughput approach. In the automated settings, the whole procedure could be completed in just 20 minutes. ${ }^{73}$ The overall procedure is simple, robust, and reduces the operational time significantly, and is, therefore, very helpful for a quick diagnosis.

Micro RNA (miRNA) are major regulators of biological processes and act through the regulation of gene expression, and hence can be used as biomarkers for disease diagnosis. ${ }^{74}$ miRNA interact with various signaling pathways during viral infections. Some viruses encode miRNAs, which are also crucial in viral infections. These small molecules play an important role during infection as these molecules can modify the cellular environment and are generally present in the body fluids like blood, saliva, urine, etc., and therefore allow non-invasive detection. MNPs have been successfully employed for the detection of miRNAs from body fluids and have been reviewed elsewhere. ${ }^{75}$ Therefore, the MNP-based extraction of nucleic acids is a promising alternative for the high-throughput extraction of nucleic acids from patient samples and can expedite the molecular diagnosis of viral infections.

3. SDS-PAGE and mass spectrometry-based detection of viral proteins. MNPs labeled with antibodies or specific binding proteins that can hybridize a candidate target antigen or other virus-specific proteins present on the viral particle are being 
used for the detection of viral infection. Such methods are based upon the identification of the bound protein using SDS-PAGE or mass spectrometry. ${ }^{76}$ However, the antibody-conjugated magnetic nanoparticle device may serve as an efficient probe for the extraction of viral particles by taking advantage of the MNPs' large surface area-to-volume ratio. ${ }^{77}$ The isolated viral particles may also be used for SDS-PAGE and on-bead mass spectrometric analysis.

Chou and colleagues (2011) functionalized the surface of iron oxide MNPs with monoclonal antibodies specific to the hemagglutinin protein of H5N2. ${ }^{78}$ Functionalized MNPs were then capped with methoxy-terminated ethylene glycol to suppress non-specific binding. Using these hemagglutinin antibodies-coated MNPs and magnetic separation, H5N2 viruses were successfully isolated. Virus particles were then characterized using SDS-PAGE visualization, liquid chromatography-tandem mass spectrometry (LC-MS/MS), and peptide sequence recognition. The antibody-conjugated MNPs with closely related recombinant H5N1 viruses had a high affinity for the H5N2 virus without cross-reactivity. Though SDS-PAGE and LC-MS/MS could both detect the target, LC-MS/MS was more sensitive with a viral load of $\sim 10^{3}$ (egg infective dose) $\mathrm{EID}_{50}$ per $\mathrm{mL}$, which could be detected effectively. This study brings attention to the target-specific functionalization of MNPs as an effective tool for viral extraction and suggests that monoclonal antibody-functionalized MNPs can be used to distinguish among various subtypes of virus. ${ }^{78}$

4. ELISA-based detection of antibody binding against viral antigens. The enzyme-linked immunosorbent assay (ELISA), an immunological assay, is widely used for the assessment of antibodies, antigens, proteins, and glycoproteins in biological samples. ${ }^{79}$ This is based upon the antibody-antigen interactions, where antibodies are usually conjugated with specialized tags that help in detection. The detection of HIV infection, pregnancy tests, and the assessment of cytokines or soluble receptors in supernatant or serum cells are a few examples. Magnetic nanoparticles coated with primary antibodies can hybridize a specific target antigen and can also be used as enzymes like horseradish peroxidase (HRP), for cost-effective single-step efficient detection of viral infection based on the ELISA principle. ${ }^{80}$

Nourani and coworkers have used this principle for the detection of the hepatitis B virus. ${ }^{81}$ Here, MNPs coated with anti-HBsAb (anti-hepatitis B virus surface antibody) were used to capture the HBsAg while MNPs coated with HRP-labelled secondary antibody were used to convert aminophenol into electrochemically detectable reaction products (3-aminophenoxazone (3-APZ). This electroactive 3-APZ was then transferred into an electrochemical cell where it was tested by employing cyclic voltammetry with a limit of detection (LOD) of $0.9 \mathrm{pg} \mathrm{mL}{ }^{-1}$. ${ }^{81}$ Similarly, Duan and colleagues developed a paper-based nanozyme strip for the efficient detection of the Ebola virus. ${ }^{82}$ In this case, antibodies specific to the glycoprotein of the Ebola virus were coated on the MNPs, which were then immobilized on an electrochemically active paper substrate to develop an MNP-based immunochromatographic strip or a nanozyme-strip. These MNP-based nanozyme probes recognize their target and the magnetic properties of the MNPs help in the quick separation of a target. The peroxidase-like activity of the enzyme probe can catalyze the peroxidase activity resulting in simplification and hence visualization. When a nanozyme strip comes into contact with a target sample or molecules, an electrochemical signal is generated, which is detected utilizing cyclic voltammetry. ${ }^{82}$ As compared to standard strips, these MNP-based immunochromatographic strips enhanced the assay sensitivity by 100 fold. This is a simple and robust tool for clinical disease diagnosis and its accuracy is comparable to ELISA-based detection systems. Similarly, Hung and coworkers synthesized magnetic $\mathrm{MnFe}_{2} \mathrm{O}_{4}$ nanoparticles for the rapid and effective detection of influenza virus infection. ${ }^{83}$ Herein, the authors developed a microfluidic lateral flow enzyme-linked immunoassay in which $\mathrm{MnFe}_{2} \mathrm{O}_{4}$ MNPs were used to isolate the viral particles and were later quantified using the immunoassay.

A magnetic nanozyme-linked immunosorbent test for the identification of viral particles was developed by $\mathrm{Oh}$ and collaborators. ${ }^{84}$ In this context, the authors synthesized silicacoated MNPs that were further hybridized with gold NPs. The magnetic nanoparticles were used to detach the viral particles, and the quantification was done based on the enzymatic activity of gold nanoparticles. The detection limit of this technique was $2.6 \mathrm{PFU}$ per $\mathrm{mL}$ as reported.

5. LSPR based detection. Since electromagnetic radiation excites monodisperse spherical noble metal nanoparticles in solution, their conduction electrons collectively oscillate, resulting in wavelength-selective absorption and scattering of the incident radiation. This phenomenon is generally known as localized surface plasmon resonance (LSPR). ${ }^{85}$ LSPR is one of the peculiar physical properties of metal NPs that results from the oscillation of electrons and is directly affected by the size and shape of the nanoparticle. ${ }^{85,86}$ Mainly, metal oxide MNPs do not show any spectroscopic absorbance while gold and silver nanoparticles (Au/AgNPs) with known SPR are commonly used for optical applications. ${ }^{87}$ Changes in LSPR peaks are a result of Au/AgNPs aggregation, which is mediated upon interaction with viral proteins. Several bio-analytical applications based on the SPR of AuNPs have been reported ${ }^{86}$ As a result, gold or silver nanoparticles and MNPs can be mixed for the colorimetric or spectroscopic quantification of the target nucleic acid or protein and then can be used for the clinical diagnosis of viruses. These hybrid nanoparticles demonstrate the properties of SPR along with the magnetic properties of MNPs that assist in the isolation and identification of viral infections.

The Sabouri group has used this concept to dope MNPs with gold NPs and then the surfaces of the doped MNPs were functionalized with antibodies of HBsAg to isolate the HBsAg viral antigen. ${ }^{88}$ Later, the SPR of these doped nanoparticles was used to quantify HBsAg in blood, serum, and plasma by directly measuring the shift in the SPR peak. Researchers were able to detect minimal HBsAg concentrations by using this technique. ${ }^{89}$

6. SERS-based detection. Raman scattering or the Raman effect is the inelastic scattering of photons by matter, which 
means that there is an interaction of energy and a transition in the path of light. One of the drawbacks of the influence of the Raman effect is that it is a very mild phenomenon..$^{90}$ Around one in $10^{7}$ photons is scattered by Raman. The intensity of the Raman signal is generally very low due to the lower concentrations of the analyte or weak Raman scattering. Therefore, surface-enhanced Raman spectroscopy (SERS) is all about amplifying Raman molecular signals by many orders of magnitude. SERS is a method under which molecules experience far higher scattering efficiencies while adsorbed into metal colloidal nanoparticles or rough metal surfaces. In recent years, SERS has evolved as a major non-invasive tool for the development of optical sensors. ${ }^{91}$ The most attractive features include low-cost equipment that is compact and capable of highly sensitive and specific rapid clinical diagnosis. Nanostructured metal-dielectric surfaces have near-surface region electromagnetic field localization, resulting in giant signal amplification, usually by $10^{6}$ times. $^{92}$ SERS-substrates consist of colloid particles with varying sizes and forms, composite nanoparticles with coreshell structures, and solid-state substrates with intermittent metallic and dielectric layers of both stochastic and periodic structures. ${ }^{91}$

The ideal metal portions of the SERS-substratum have been considered to be gold and silver because they have several exclusive physical properties, i.e., very negative, true, and small, imaginative components of permittivity. As a result, for the spectroscopic quantification of target nucleic acids or proteins for viral diagnosis and detection, MNPs have been combined with gold or silver nanoparticles. ${ }^{93}$ In recent years, extremely sensitive and fast SERS technology has been applied to establish sensors for the detection of viruses. SERS reaches signal enhancements of $10^{6}-10^{9}$ times, yielding exceptional sensitivity. ${ }^{94}$ The influenza virus identification, where hemagglutinin aptamers have reliable information of the influenza virus, is one such example of SERS-based detection. ${ }^{95}$ An aptamer called RHA0385 (recombinant hemagglutinin from H5N1 influenza strains) has been shown to provide a high strain tolerance for all recombinant hemagglutinins and most of the influenza virus strains, i.e. H1N1, H3N2, and H5N1. To ensure high sensitivity, a sandwich-type assay has been developed with primary aptamers, influenza viruses, and secondary aptamers. The doped magnetic nanoparticles of the SERS substrate were conjugated to primary aptamers, which can interact with influenza viruses. This complex was allowed to bind with secondary aptamers labeled with Raman-active molecules, thus forming a sandwich-type complex that can be detected by SERS. The abundance of both the primary and secondary aptamers, which indirectly correlates with the viral load, influences the SERS signal, i.e., the viral load-dependent SERS signal. For example, as measured with the H3N2 virus, the detection limit was as low as $10^{-4}$ hemagglutination units per probe. The recognition of multiple influenza virus strains, including $\mathrm{H} 1, \mathrm{H} 3$, and $\mathrm{H} 5$ hemagglutinin subtypes, is supported by this kind of aptamer-based sensor. ${ }^{95}$

7. Other MNPs-based detection techniques. Wacker and coworkers (2007) combined two conventional techniques, i.e., ELISA and PCR, along with MNPs-based magneto immune
PCR (M-IPCR) for the separation and detection of the hepatitis B virus. ${ }^{96}$ For this purpose, antibody-functionalized biogenic magnetosome nanoparticles were synthesized. The M-IPCR was carried out by simultaneously tagging the antigen with the reagent for readout, i.e., a conjugate consisting of a particular antibody and DNA fragment in the presence of antibodyfunctionalized magnetosomes. Using M-IPCR, HBsAg was successfully detected in the human serum with a detection limit of $320 \mathrm{pg}$ per $\mathrm{mL}$, which was many times more sensitives as compared to other ELISA-based methods. ${ }^{96}$ Similarly, Tuan and colleagues (2009) developed a DNA enrichment method by functionalizing oligonucleotides on MNPs. In this case, the group developed an electrochemical DNA sensor for the rapid and on-site detection of viral particles in a biological medium. ${ }^{97}$ On the other hand, Yang and colleagues (2009) used bio-activated MNPs to enhance the specificity of virus detection. MNPs can be coated with bio-probes like a labeled antibody, oligonucleotides, etc., which can recognize and bind to homologous or heterologous target molecules. ${ }^{98}$ In the presence of alternating magnetic fields (AMF), these MNPs rotate and generate a centrifugal force that can be varied by adjusting the angular frequency of the rotating MNPs. Angular frequency directly regulates the centrifugal force and it is adjusted in such a way that centrifugal force is generated to remove the poorly bound bio-targets and hence can effectively suppress the cross-reactivity of bio-targets. These forces can be manipulated to isolate and extract the desired biomolecules.

Furthermore, Thomson and colleagues (2011) developed an amplification-independent nucleic acid detection method for the clinical diagnosis of pathogens. ${ }^{99}$ Herein, MNPs and fluorescent polystyrene nanoparticles were modified with DNA probes, which were capable of hybridizing with either end of the target DNA and subsequently forming a sandwich-like complex, i.e., target DNA, in between MNPs. The concentration of target DNA was determined by counting individual and aggregated fluorescent nanoparticles on a flat glass surface inside a fluid chamber and target DNA in the range of $0.8 \mathrm{pM}$ could be detected. ${ }^{99}$ Similarly, Ying Fen and colleagues (2014) synthesized multiple antigenic peptide-coated SPIONS to capture, purify and detect proteins of the herpes simplex virus. ${ }^{100}$ The assay is a label-free rapid detection tool and is known as magnetic bead aggregation (MBA) assay. The MBA essay is capable of detecting proteins and the HSV-1 virus responsively and rapidly. Highly uniform superparamagnetic beads made it possible to easily detect aggregate quantities, one particle at a time, using light scattering. Biotinylated albumin has been observed for six orders of magnitude with reaction times as short as 2 minutes with high sensitivity and detection limit in the femtomolar range.

A bioinspired NP-based approach for the targeting and enrichment of viral pathogens has also been developed by Chen and colleagues (2017). ${ }^{101}$ Here, the authors integrated cell membrane, poly(lactic-co-glycolic acid) (PLGA) polymers, and SPIONs, to form a composite. These composite nanoparticles have biomimetic properties, which were then used to exploit host-pathogen interactions for virus binding, thus 
enabling the extraction and enrichment of non-disrupted viral samples. Similarly, ferromagnetic resonance (FMR)-based biosensors for DNA detection have been reported by Tian and group (2018). ${ }^{102}$ In this case, MNPs coated with antibodies target the DNA complexes, which ultimately leads to solution aggregation, and increases the resonance area measurable by FMR. Likewise, Babamiri and colleagues (2018) developed a sandwich-type electrochemiluminescence-based immunosensor for the detection of the hepatitis B virus. ${ }^{103}$ In this context, the authors synthesized MNPs modified with carboxy groups, and then they were functionalized with the primary HBsAg antibody. They were then incubated with a secondary antibody that was functionalized with quantum dots to form a sandwichtype complex. These quantum dots were used to amplify enhanced chemiluminescence (ECL) signals, which were then expended to detect HBsAg.

Zhang and coworkers (2018) have described a magnetic resonance light scattering-based optical sensor comprising biomimetic polydopamine-coated MNPs for the detection of the hepatitis A virus. ${ }^{103}$ The sensor developed by the group has been able to detect the hepatitis A virus in concentrations as low as $6.2 \mathrm{pmol} \mathrm{L}^{-1}$. On the other hand, Zhong and colleagues (2020) synthesized antibody-conjugated MNPs for the detection of the spike protein of SARS CoV-2. Here, the rapid detection of the complex was done through the use of MPS (magnetic particle spectroscopy) with a limit of detection of $0.084 \mathrm{nM}$ $(5.9$ fmole $) .{ }^{104}$

\section{B. Magnetic nanoparticles: their role in antiviral therapeutics}

MNPs are generally nonvirulent, non-toxic, and initiate minimum or no immune responses in biological systems, which make them excellent biocompatible nanomaterials. ${ }^{105}$ Such exciting properties of MNPs enhance their cargo-carrying capacity, improve cellular penetration, and increase the ability to deliver drugs when exposed to an external magnetic field. The applications of superparamagnetic MNPs for viral eliminations and as antiviral agents have also been reported in recent years. Fig. 3 shows a schematic representation of the various mechanisms to control viral infections using MNPs.

1. MNPs as an antiviral agent. Magnetic nanoparticles are being used to eliminate a broad range of pathogenic microbes like bacteria, fungi and in recent years their applications have also been extended to eliminating and controlling viral particles. ${ }^{106,107}$ To control or eliminate viruses using MNPs involves several strategies and methods. Commonly used methods to control viruses include inactivating them directly, preventing viral attachment and penetration to the host cell, and/or blocking viral RNA synthesis and budding (Fig. 3). Such antiviral activities can be achieved by surface modification of MNPs using desired biomolecules.

Bromberg and colleagues (2012) developed surface-modified core-shell MNPs such that these modified MNPs could directly bind to viral particles and can then be used to eliminate the viruses. ${ }^{108}$ For this purpose, the authors used aziridines, poly(hexamethylene biguanide) (PHMBG), and low molecular weight ethyleneimines to covalently bind the surface of MNPs.

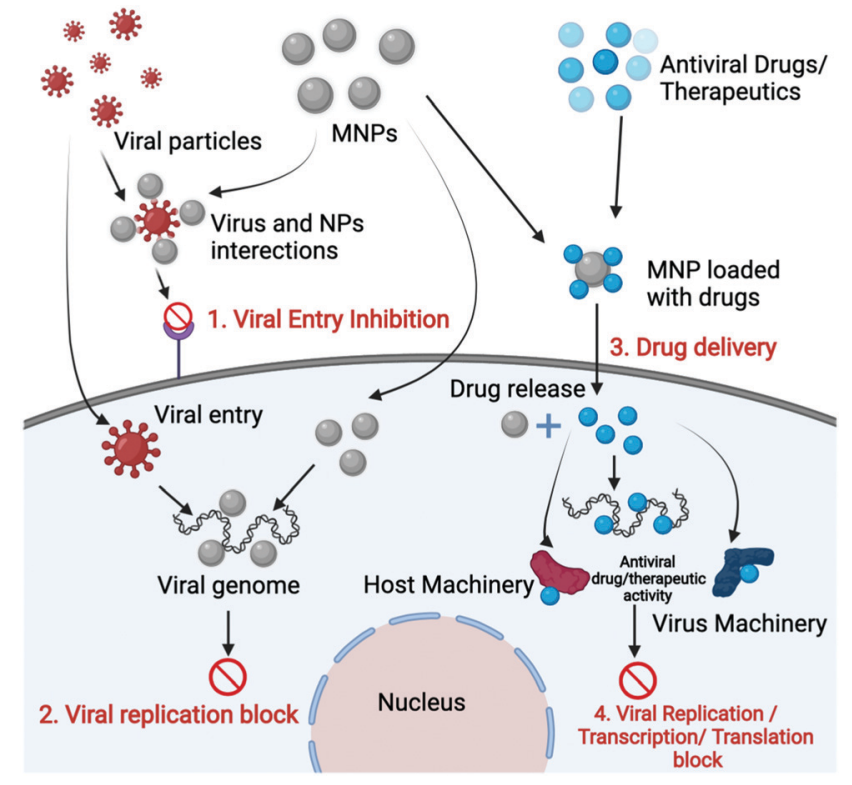

Fig. 3 Schematic representation of the various mechanisms to control viral infections using MNPs.

Aziridines and ethyleneimines have been widely exploited for virus inactivation in vaccine development and chemotherapeutic agents; therefore the authors have explored their antiviral properties by coating them on MNPs surfaces. The core-shell structure of MNPs consists of magnetite clusters as the core and functional silica shells provide the base for covalent modifications. These surface-bound functional groups of MNPs interacted with viral glycoproteins and demonstrated antiviral activity in which the surface charge played an important role in the inactivation of viral particles. Further, it was demonstrated that poly-cationic and functionalized MNPs can inactivate different kinds of viruses, such as herpes simplex virus (HSV-1), bacteriophage MS2, enveloped viral hemorrhagic septicemia virus (VHSV), and non-enveloped infectious pancreatic necrosis virus (IPNV). Electrostatic interactions between cationic charged MNPs and negatively charged virions played a major role in the inactivation of viral particles. The presence or absence of the lipid envelope and the size of the virion significantly influence the virucidal efficiency of antiviral agents and the lipid envelope makes virions susceptible to interactions with nanoparticles. ${ }^{108}$ Moreover, the aziridine groups bind to viral DNA/RNA and inhibit the replication/transcription of the viral nucleic acids and the binding of aziridine to DNA/RNA generally occurs through covalent or ionic interactions. This results in the opening of the imidazole ring structure of the guanine molecule, which acts as a stop signal for DNA and RNA polymerases, thereby inhibiting replication or transcription, respectively. In the case of PHMBG-modified MNPs, hydrophobic groups of PHMBG helped to reduce the polarity of the virion particles, which resulted in their aggregation and inactivated the virus. The virus and nanoparticle complexes were also efficiently removed from the aqueous medium by simple magneto-collection using an external magnetic field. 
Kumar and colleagues (2014) used polymer-coated monodispersed iron oxide MNPs to inhibit the H1N1 influenza virus. ${ }^{109}$ Herein, polyethylene glycol (PEG) coating, polyvinyl pyrrolidine (PVP) coating, or pristine iron oxide NPs were used. Polymer coating on the MNPs surface improved the biocompatibility and also helped in their interactions with viral nucleic acids. However, the biocompatibility of PEG- and PVP-coated MNPs was much higher as compared to the pristine MNPs. This study revealed that the negatively charged $\mathrm{Fe}_{3} \mathrm{O}_{4}$ NPs strongly bind with the surface glycoprotein of the H1N1 virus and this binding results from electrostatic interactions. ${ }^{109}$ Further, PEG- and PVPcoated MNPs assisted the nanoparticle system in endocytosis and cellular binding. The authors reported that the virucidal effect of MNPs was due to the direct interaction of polymer-coated MNPs with viral RNA, which resulted in the inhibition of viral RNA replication and the gradual reduction of virion particle formation. The interaction of MNPs with the H1N1 influenza virus was due to the change in the surface charge of the MNPs because of the addition of polymer. Such interactions of MNPs with the virus and its RNA also rely on the physicochemical properties like shape, size, and surface charge of the MNPs. The polymer used for coating MNPs also significantly affects the interactions of MNPs with viral particles, and a combination of these parameters can prevent the multiplication of the virus. These findings revealed that the PEG- and PVP-coated MNPs were highly effective for inhibiting the H1N1 viral multiplication as compared to pristine nanoparticles. Overall, the results obtained suggest that MNPs with diverse shapes or sizes with a variety of surface modifications can be used for the control or treatment of viral infections and can play a significant role in developing novel antiviral methods.

Similarly, Rishikesh Kumar and coworkers (2018) used iron oxide nanoparticles surface coated with glycine for the elimination of the H1N1 influenza virus. ${ }^{53}$ These authors synthesized the iron oxide NPs in the size range of 10-15 $\mathrm{nm}$ and reported that these NPs were effective in controlling several pandemic influenza strains. Their study revealed around an 8 -fold reduction in virus plague within $24 \mathrm{~h}$ of virus infection when treated with iron oxide NPs. It was also reported that smallersized iron oxide NPs in lower doses inhibited the viral infectivity more efficiently than the larger-size and higher doses of nanoparticles. The group proposed that NPs of smaller size could interact better with the viruses and their antiviral activity could be due to a size-dependent interaction of MNPs with the virus or viral RNA. Though the specific mechanism of antiviral activity is still not clear, either the interaction of iron oxide NPs with -SH groups present on viral surface proteins, or the interaction with viral RNA might have inactivated the virus, which ultimately resulted in a reduction of the $\mathrm{H} 1 \mathrm{~N} 1$ influenza virus population. The simple method of preparation and effectiveness of glycinecoated iron oxides NPs against several strains of influenza can make these MNPs useful for controlling other viral pathogens.

Nanoparticles can have enzyme-like activity that can be controlled by tuning their physicochemical properties. ${ }^{110,111}$ Nanomaterials with intrinsic enzyme-like activities are generally known as nanozymes. ${ }^{112}$ Such enzyme-like activity of nano-materials results from their catalytic activities similar to peroxidase, catalase, oxidase, etc., and several types of nanoparticles like metals, metal oxides, and metal-carbon compounds have been reported to have such activities. Nanomaterials with catalytic properties can be used as artificial enzymes. Interestingly, nanozymes generally display characteristics that are similar to natural enzymes, including substrate or optimal $\mathrm{pH}$ and temperature. Iron oxide $\left(\mathrm{Fe}_{3} \mathrm{O}_{4}\right)$ MNPs are the most commonly used NPs as nanozymes, which generally perform two enzyme-like activities, specifically, catalase and peroxidase activities. ${ }^{113,114}$ Nanozymes have successfully been used for diagnosis, detection, antibacterial activity, and tumor therapy. Recently, Qin and colleagues (2019) reported the synthesis of iron oxide NPs-based nanozymes (IONzymes) for the inactivation of the influenza virus. ${ }^{115}$ Herein, the authors used the peroxidase and catalase properties of iron oxide NPs to induce lipid peroxidation of the viral envelope and terminate the integrity of neighboring proteins, involving neuraminidase, hemagglutinin, and matrix protein, ultimately triggering the neutralization of influenza A viruses. The antiviral activity of IONzymes was also explored against 12 different influenza strains and it successfully neutralized them. Later, to test the ability of IONzymes to control the spread of the influenza virus, IONzymes were introduced into face masks as an active antiviral component. Interestingly, face-masks having IONzymes showed improved virus protection against three different strains that pose a threat to humans, including H5N1, H7N9, and H1N1. ${ }^{115}$ Hence, this study has not only shown the antiviral properties of IONzymes in lab-scale testing but incorporating IONzymes into face-masks also proved very effective in the product-based applications.

Abo-zeid and coworkers conducted a model study to determine the potential of iron oxide NPs to control and treat SARSCoV-2 viral infections. ${ }^{116}$ Here, they studied the interactions of $\mathrm{Fe}_{2} \mathrm{O}_{3}$ and $\mathrm{Fe}_{3} \mathrm{O}_{4}$ iron oxide NPs with the structural protein of SARS-CoV-2 and hepatitis $\mathrm{C}$ virus (HCV), which are essential for viral attachment and host cell entry. Their docking model study showed that $\mathrm{Fe}_{2} \mathrm{O}_{3}$ and $\mathrm{Fe}_{3} \mathrm{O}_{4}$ iron oxide NPs efficiently interact with SARS-CoV-2 S1-receptor-binding domain (RBD) as well as HCV glycoprotein E1 and E2 by forming stable complexes. Hydrophobic interactions and hydrogen bonding between MNPs and amino acids played the main role in forming the iron oxide NPs and virus complex. $\mathrm{Fe}_{3} \mathrm{O}_{4}$ formed the most stable complex with SARS-CoV-2 S1-RBD, whereas in the case of HCV structural glycoprotein $\mathrm{E} 1$ and $\mathrm{E} 2, \mathrm{Fe}_{2} \mathrm{O}_{3}$ formed the most stable complex due to their lower free energy. Authors further hypothesized that these interactions may lead to conformational changes in the viral structural proteins and ultimately inhibit virus entry into host cells, limiting virus replication and further spread. This study revealed that MNPs could be potential candidates for antiviral treatment or for managing and preventing viral infections. ${ }^{116}$ Such antiviral properties of MNPs can also be extended to the treatment of other viruses.

2. MNPs as a delivery agent. Nanoparticles can be designed as a smart delivery carrier by manipulating their size, properties, and surface functionalization. ${ }^{117}$ These smart nano systems can deliver the drug to the desired locations in the tissues or organs 
and release the cargo at a predetermined rate for a specific period. ${ }^{117,118}$ Further, the system can be used in active or passive mode and can deliver the cargo locally, as well as systemically. ${ }^{119}$ Ryoo and colleagues (2012) demonstrated the iron oxide nanoparticle-assisted delivery of therapeutic DNAzyme for the control and treatment of HCV. ${ }^{120}$ DNAzymes are therapeutic antisense nucleotides that are specific to the pathogen's genome and are capable of inhibiting the target gene expression. Antisense oligonucleotides hybridize to mRNA and form DNA-RNA hybrid duplexes, ultimately leading to cleavage by using cellular RNAse H. This can be used to inhibit the gene expression essential for virus replication. Here, the authors have synthesized core-shell iron oxide NPs, and cell-penetrating peptides along with a synthetic DNAzyme and fluorescent dye were covalently bound to their surface. Cell-penetrating peptides can specifically transport hydrophilic molecules across the eukaryotic cell membrane and enhance the overall cellular uptake efficiency, while conjugated dye assists in tracking the therapeutic nanoparticles using fluorescence imaging. Further, the magnetic core can also be used for tracing NPs via magnetic resonance imaging. In order to inhibit the viral replication, the Ryoo group targeted the NS3 gene, which codes for a protein having helicase and protease activities. ${ }^{120}$ When DNAzyme was delivered in Huh-7 Luc-Neo hepatoma cells using iron oxide NPs, it resulted in a reduction of the NS3 gene expression as high as $91 \%$ and viral replication was downregulated. It was also reported that the nanoparticle complex does not elicit any undesired immune responses in Huh-7 cells and has a significantly higher suppression efficacy than the free DNAzyme.

Jayant and colleagues (2015) have developed a novel iron oxide-based nanocarrier for the treatment of Neuro-acquired immune deficiency syndrome (AIDS). ${ }^{121}$ Generally, human immunodeficiency virus (HIV) replication plays an important role in neurological diseases, and the central nervous system (CNS) is one of the main viral reservoirs. Therefore, virus elimination from the CNS is essential for the treatment of Neuro-AIDS. However, treatment therapies for such brain disorders aren't very successful because of the presence of the blood-brain barrier (BBB), which generally does not allow drug molecules to pass through and get into the target site in the brain for therapeutic action. ${ }^{122}$ This is the main drawback of several brain therapies. Therefore, there is a need for a drug formulation that can easily pass through the BBB and can act swiftly in the CNS. The small size of nanoparticles that can easily pass through the $\mathrm{BBB}$, can be used as a potential delivery vehicle for brain disorders. ${ }^{123}$ Jayant and colleagues layer-bylayer (LbL) assembled a latency-breaking agent (vorinostat) and the anti-HIV drug (tenofovir) on iron oxide NPs, eventually forming a magnetically guided nanocarrier to achieve persistent drug release. ${ }^{121}$ Herein, ultrasmall $(10 \mathrm{~nm})$ iron oxide NPs were synthesized to deliver the drugs across the BBB, and were subsequently released for a longer period. Electrostatic interactions between the MNPs and the polyelectrolytes were the main driving force for multilayer self-assembly and were determined by zeta potential analysis. The pharmacokinetics release studies showed the sustainable release of drugs from LbL assembled nanocarriers for up to 7 days and successfully eliminated HIV up to 33-fold, which was determined through the quantification of p24 antigen in the human astrocytes (HA) infection model. The small size of iron oxide nanoparticles assisted the nanocarrier to pass through the blood-brain barrier and increase the transmission ability up to $37.95 \% \pm$ $1.5 \%$. On the other hand, to achieve higher transmigration of the nano-formulation through the blood-brain barrier, the authors augmented the essential parameters of the magnetic field and time of application, and more than $40 \%$ of drug delivery was achieved. Therefore, this study proves that latencybreaking agents can be packaged into nanoparticles in combination with an antiretroviral drug and can successfully be used to eliminate the viral particles, even across the BBB.

Similarly, Fiandra and colleagues (2015) coated the iron oxide NPs with an amphiphilic polymer PMA for the delivery of the antiretroviral drug enfuvirtide (Enf) across the BBB. ${ }^{124}$ Enf inhibits HIV fusion with cells and non-selectively stops the virus entry into the cells. However, Enf is normally incapable of entering the cerebrospinal fluid and the $\mathrm{BBB}$, which is generally impermeable to antiretroviral drugs due to its high molecular weight. Therefore, the drug was covalently attached to the polymer-coated iron oxide NP core, and a fluorescent dye was also tagged to polymer-coated iron oxide NPs to monitor the translocation of the nanocarrier across the BBB. The study reported the permeation of nano-formulated Enf across the BBB increased up to $170 \%$ after $3 \mathrm{~h}$ of incubation. It is also stated that the internalization of the MNPs-based nanosystem is mainly governed by passive diffusion, possibly guided by the absorption of the amphiphilic coating on the cell membrane. Though the mechanism for the disassociation of Enf from the polymer in the endothelial cells has not been understood, it could be due to the degradation of the PMA shells having the drug peptide. Further studies need to be performed to evaluate the antiviral effectiveness of Enf across the BBB; however, these studies have shown important breakthroughs toward NeuroHIV eradication from the CNS reservoir and the small size of MNPs with surface functionalization ability can be a suitable drug delivery vehicle across the BBB.

3. Magnetic hyperthermia for virus elimination. MNPs of ultra-small sizes generally do not exhibit any magnetic behavior by themselves. However, the application of an external magnetic field can induce strong magnetism in the particles, which is known as superparamagnetism. ${ }^{47,125}$ Heat-associated conditions in living systems, where the temperature of living cells significantly increases beyond the average temperature, are commonly called hyperthermia. ${ }^{126}$ When an external alternating magnetic field (AMF) is applied to superparamagnetic nanoparticles, the direction of magnetization flips randomly between the parallel and anti-parallel orientations, allowing the transfer of magnetic energy to the MNPs in the form of heat, known as magnetic hyperthermia. ${ }^{127}$ This phenomenon can be used in vivo to increase the localized temperature of tumor tissues to destroy specific tumor cells. ${ }^{51}$ Hyperthermia has successfully been used in the past for the treatment of cancer, bacterial infections, and other diseases. Normally, the temperature of the target cells is increased beyond $41{ }^{\circ} \mathrm{C}$ that results in 
cell death. ${ }^{126}$ Overheating of the body can cause sweating, fever, or organ failure; however, MNPs-based localized heating overcomes these side effects and kills the target cells in a controlled manner. The use of magnetic hyperthermia has been extended to treat viral infections and it can be very effective in controlling viral pathogens.

Williams and colleagues (2013) developed a novel therapeutic strategy to eliminate the virus using magnetic field-induced hyperthermia using MNPs. ${ }^{128}$ Here, the authors used biocompatible superparamagnetic nanoparticles named FeraSpin $\mathrm{R}$ that has excellent cellular uptake properties. When FeraSpinR nanoparticles were exposed to an external magnetic field, localized heat was generated, which ultimately killed the cytotoxic $\mathrm{T}$ cells (CTL) that were HIV-infected. The study revealed that alternating magnetic field contact subsequently led to the death of CTLbound target cells via direct thermal ablation, or enhanced their cytolytic activity, ultimately reducing the virus population. The authors also reported that the cellular uptake of MNPs by target cells occurred via the endocytic pathway, and protamine sulfate and lipofectamine were used to enhance the cellular uptake of nanoparticles. Though magnetic hyperthermia has long been used to treat cancer, here, the authors have applied this technique to the viral disease HIV. Further, it is hypothesized that thermotherapy might increase the temperature of the HIVinfected CTLs and directly induce cell death. ${ }^{128}$ Williams and coworkers, therefore, suggested that MNP-based hyperthermia may serve as a treatment for the removal of HIV-positive cells that were latently infected. Recently, Aminul Islam and colleagues highlighted an MNP-based therapeutic approach to eliminate SARS-CoV-2 by the application of a magnetic field. ${ }^{129}$ MNPs interact with the structural membrane protein of SARS-CoV-2 in the presence of an external magnetic field and alter the orientation of single-stranded RNA. These interactions can neutralize viral infections. Hence, these studies signify the potential of magnetic hyperthermia and magnetic field-based therapies to prevent and control viral infections and pandemics.

4. The removal of viral particles using MNPs. Nanoparticles labeled with antibodies, aptamers, protein, and/or carbohydrates have been explored to remove pathogens or viral particles from contaminated water or other sources and have been used as components of a filter for viral or bacterial removal. ${ }^{130,131}$ Nanomaterials can also be used to remove viruses or other pathogens from biological systems. In recent years, significant progress has been made towards the use of MNPs for the removal of viral particles from blood plasma. Magnetic nanoparticles have shown excellent adsorption performances for the removal of bacteria or viruses. The major advantage of MNPs over other NPs for the removal of viral particles is that these are more resistant to corrosive, acidic, and oxidant conditions, and have better biocompatibility. ${ }^{105}$ Most importantly, the magnetic properties of MNPs, which metal nanoparticles do not have, make them an ideal tool for removing viral particles from biological systems. MNPs can easily be separated from the solution along with their attachments with the help of an external magnetic field. Metal NPs can have antimicrobial properties and hence can be used as therapeutic agents; e.g., silver NPs are used for wound care. ${ }^{132}$ However, because of the cytotoxic properties of metal NPs, their unregulated presence in the environment or biological systems can develop unwanted consequences for human health and ecological biodiversity, ${ }^{133,134}$ and therefore, MNPs can be a potential substitute for metal NPs for such applications.

In this context, Park and colleagues (2014) encapsulated superparamagnetic $\mathrm{Fe}_{3} \mathrm{O}_{4}$ nanoparticle clusters within a silica shell of about $0.1 \mu \mathrm{m}$ thickness to develop a magnetic hybrid colloid (MHC) ${ }^{135,136}$ In this case, the encapsulation of MNPs with silica protects the NP clusters, and their aminopropyl groups are used for surface functionalization to attract gold or silver NPs, which self-assemble to form a hybrid complex. In this manner, the authors synthesized MHC decorated with silver NPs of various sizes. Silver nanoparticles of hybrid colloids were used as disinfectants due to their antimicrobial activity, whereas MNPs of the hybrid colloid were used to recover the entire complex from the environment. The effectiveness of AgNP-MHC was evaluated by their ability to inactivate the bacteriophage MS2, X174, adenovirus serotype 2 (AdV2), and murine norovirus (MNV). These above-mentioned targets were exposed to AgNP-MHC for various periods under different environmental conditions and their antiviral activity was analyzed by plaque assay as well as real-time TaqMan PCR. The study reported that AgNP-MHCs successfully inactivated the bacteriophages and other target viruses, and later AgNPMHCs were successfully recovered from experimental conditions using a magnetic field. ${ }^{137}$ The antiviral activity of silver ions in the magnetic hybrid colloid was due to their chemical adsorption on the bacteriophages. ${ }^{135}$ Silver ions form a complex with the thiol groups on the viral capsid, which ultimately leads to the generation of reactive oxygen species (ROS) and inactivates the viruses. Besides, the size and concentration of the AgNPs in the AgNP-MHCs are crucial for achieving the highest antiviral activity.

Similarly, Delaviz and colleagues (2015) extended the application of MNPs for the removal of hepatitis C virus (HCV) particles from human plasma samples. ${ }^{138}$ The authors used a synthetic DNA aptamer that precisely recognizes and combines E1E2 glycoprotein, with starch-coated MNPs. Nucleic acid aptamers are small oligonucleotides that can be synthesized to recognize and bind to specific biomedically important proteins. Their specificities are comparable to the antibodies; however, these are better in terms of size, synthesis as well as desired modifications. These aptamer-conjugated MNPs were used for capturing and isolating hepatitis $\mathrm{C}$ viruses from human plasma samples using an external magnetic field under in vitro conditions. It resulted in a significant lowering of the viral loads; a capturing efficiency as high as $91 \%$ was reported. ${ }^{138}$ Therefore, virus-specific aptamer-conjugated MNPs can be used as a noninvasive therapy to mechanically reduce the viral loads from the patient's fluids, similar to blood dialysis or hemofiltration.

Similarly, Zhan and coworkers (2014) have developed a method for the rapid removal of pathogenic microorganisms, including viruses, using MNPs. ${ }^{139}$ In this case, the core-shell 


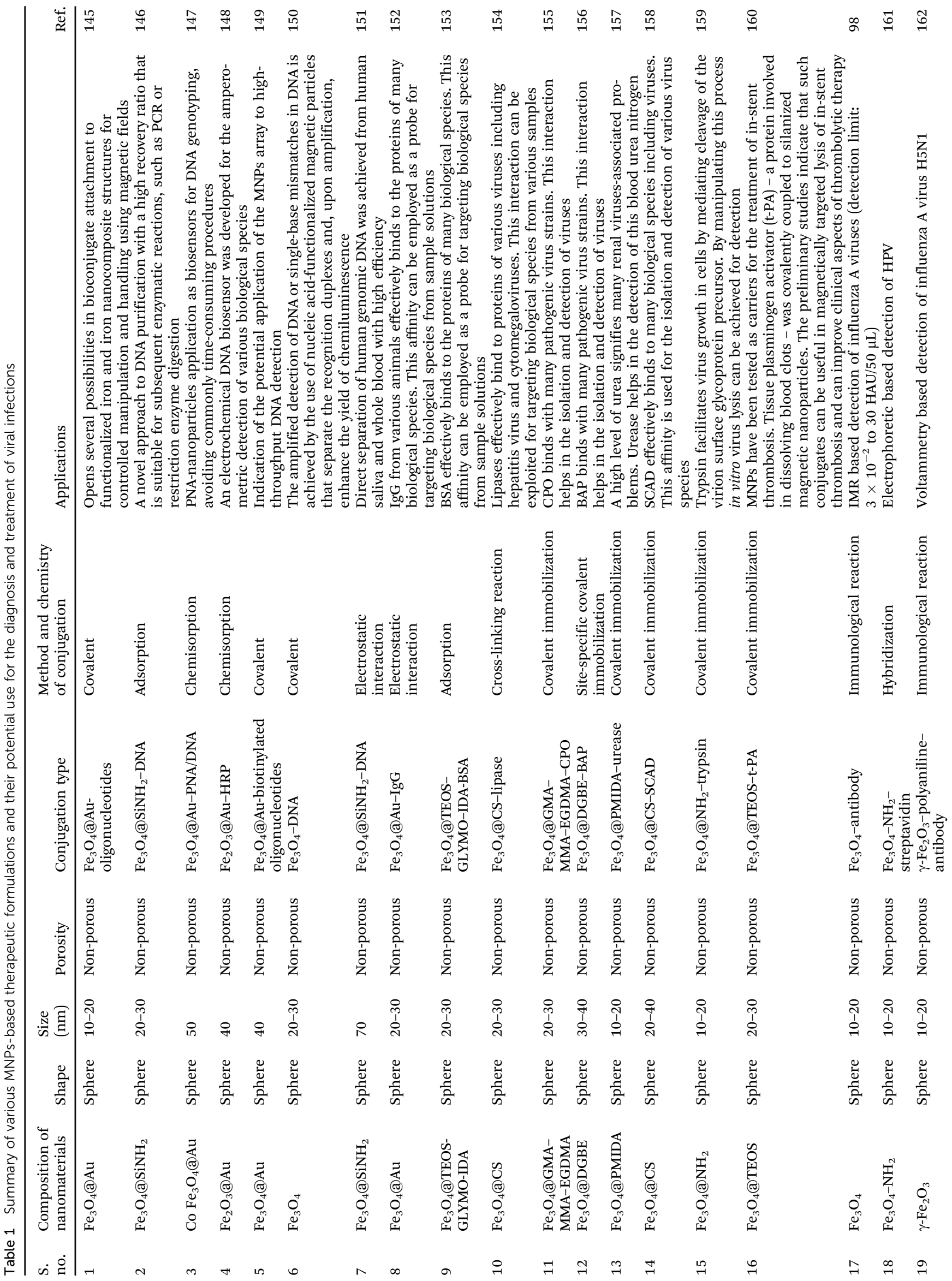


nanoparticles were prepared using a layer-by-layer assembly process, and the surface was functionalized with an amine group. Later, these core-shell MNPs were employed to capture a wide range of microorganisms including viruses like poliovirus1 , bacteriophage $f_{2}$, and various species of bacteria from water. Pathogen removal from the water was governed by the hydrophobicity, surface charge, and surface properties of microorganisms and nanoparticles. Electrostatic interactions between cationic charged MNPs and negatively charged cell membranes of microorganisms played a key role in the viral particle removal. In summary, MNPs have significant potential to act as adjunctive therapy in both viral particle removal and the eradication of virus-infected cells.

\section{The role of MNPs in the current scenario}

Various studies discussed in the previous section emphasize the use of MNPs for clinical diagnosis, detection, and antiviral therapies. Significant advances have been made in the direction of the commercialization of MNP-based products and therapies. Recently, an MNPs-based SARS-CoV-2 RNA extraction kit named Chitra magna has also been developed by Sree Chitra Tirunal Institute for Medical Sciences and Technology (SCTIMST), India. ${ }^{140}$ It works based on the fact that MNPs can bind to DNA/RNA, and using an external magnetic field, MNPs bound to these biomolecules can be quickly separated from the samples. It allows for the extraction of a highly pure and adequate amount of RNA for an accurate diagnosis. Similarly, Bandyopadhyay and colleagues at the Norwegian University of Science and Technology (NTNU) in collaboration with St. Olavs Hospital developed a silica-coated MNPs-based viral RNA extraction procedure that could expedite the diagnostic test for COVID19. ${ }^{141}$ On the other hand, Zhong and colleagues have developed SARS-CoV-2 spike protein antibodyfunctionalized MNPs as sensors for the rapid and sensitive detection of the SARS-CoV-2 virus. ${ }^{104}$ Here, the surface of the MNPs was coated with antibodies for the spike protein of the SARS-CoV-2 virus. In response to the COVID-19 pandemic, T2 Biosystems, Inc. (Lexington, MA), a company that designs NMR-based disease diagnosis platforms, recently launched the T2SARS-CoV-2 panel using MNPs. The panel is now marketable and validated in compliance with the Food and Drug Administration (FDA) ${ }^{142}$ Likewise, the magnetic properties of MNPs can be used for the separation of nucleic acids from blood samples or MNPs can also be conjugated with other nanoparticles by forming a nanohybrid to detect viral particles like SARS-Cov-2. ${ }^{143}$ MNPs coated with antibodies against a specific viral protein can be injected into the bloodstream, so they could precisely go where the virus is lurking and form a clump, which can easily be visible by MRI or NMR scans. These MNPs-based diagnostic tools are simple to use and can easily be incorporated into the device for testing purposes. Such technology could be crucial in identifying virally infected people while they are still in the early stage of infections. Keeping in mind the side effects of the NPs in the human body, Thomas Webster at Northeastern University proposed the use of iron oxide NPs, which not only could be used for targeted 
drug delivery in the human body but unused particles could be used as a nutrient supplement for the synthesis of hemoglobin in red blood cells. ${ }^{144}$

Similarly, magnetic field-induced hyperthermia can play a vital role in the neutralization of various viruses. MNPs not only create mechanical stress in cellular membrane potential but also induce the production of ROS (reactive oxygen species) that generally have antimicrobial properties, including against viruses. ${ }^{116,129}$ Therefore, such MNPs-based therapies could be used for clinical trials to prevent and control viral infections and pandemics. Several therapeutic formulations that use MNPs as their active component and can be potential tools for the clinical diagnosis, detection, and control of viral infections are summarized in Table 1. These formulations are either under lab testing or clinical trials.

\section{Conclusions and future aspects}

MNPs are an important tool and hold tremendous opportunities for both biomedical research and clinical applications. Significant advancements have been made in recent years towards viral disease diagnosis as well as treatment, due to their superparamagnetic property. Here, we have comprehensively reviewed the MNPs-based tools against viral infections, which would be helpful for developing strategies for the effective and quick diagnosis of viral infections as well as their treatment. Conventional diagnosis and detection methods usually (i) require a longer duration between sample collection and result interpretation, (ii) have low sensitivity (iii) experimental procedures are laborious, (iv) lack specificity, and (v) may have high false-negative rates. However, MNP-based tools have the potential to overcome these limitations and can play an important role in the early diagnosis of several viral infections like influenza A, hepatitis C, Ebola, etc. ${ }^{71,82,84}$ Recently, MNPs have also been used for the detection of SARSCoV-2. ${ }^{73}$ Most importantly, to achieve better results and explore their use against other viruses, suitable surface coating of MNPs is necessary, which not only gives stability to the nanoparticles but also maximizes the possibilities for use in various other applications.

MNPs, have been shown in proof-of-concept studies to be effective antiviral agents against a variety of pathogenic viruses, including influenza virus, hepatitis virus, HIV. MNPs have significant potential as an antiviral agent for the recent pandemic caused by SARS-CoV-2. ${ }^{116}$ The research community has explored MNPs based on various strategies like antiviral drug delivery and magnetic hyperthermia, which can be helpful for the treatment of viral infections. Fig. 4 shows a schematic representation of various MNPs-based strategies to control viral infections. MNPs have also successfully been tested as an active component of a commercial facemask against several viruses. ${ }^{115}$ However, in most of the studies, it has been hypothesized and demonstrated that a direct interaction between the functionalized MNPs and the virus structural proteins is important for MNP-based prevention of viral infections. These interactions

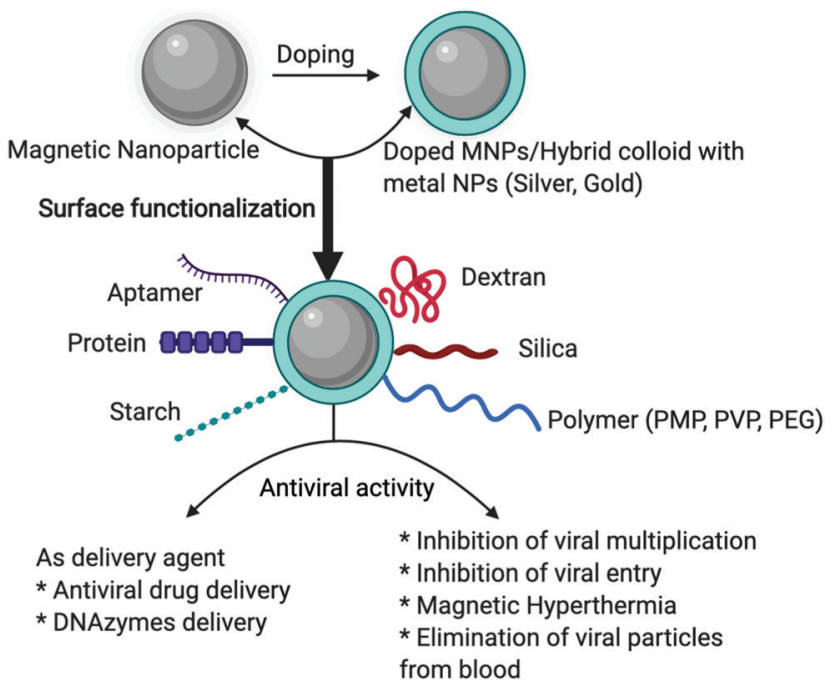

Fig. 4 Schematic representation of MNP-based antiviral approaches.

either prevent cellular entry or inhibit the replication of viral particles; however, a comprehensive evaluation needs to be performed to understand the exact mechanism of action. This will not only help to modify the MNP surface characteristics for larger and more efficient use but would help to develop more effective strategies. Nevertheless, nanoparticles-based methodologies are going to be the next suitable approach to control and prevent viral infections. Furthermore, established antiviral therapeutics that are in current use should also be explored using advances in nanotechnology and it can also be extended to other emerging novel viruses.

It is necessary to understand the cytotoxicity and possible long-term effects that may result from interactions among nanoparticles and biological systems. Thus, additional attention is required for the design, use, and disposability of the products containing MNPs or other NPs without generating new risks to the environment and human beings. Recently, we have seen that the COVID-19 pandemic has claimed a large number of lives and has caused severe health distress for the global community. ${ }^{26}$ In such a scenario, MNPs-based antiviral strategies may help to fight against novel viruses like SARS-CoV2. Generally, there is only symptomatic care or compassionate therapy for people affected by such pandemics. Thus, we need to have a rapid early detection method for contact tracing and tracking people to control the infection where the MNPs-based method can play a major role. The research community needs to focus on building highly protective tools for personal safety and environmental decontamination, which could be a smart way to cope with the present pandemic situation. Magnetic nanomaterials provide the benefit of combining traditional antiviral or viral detection approaches with modern adaptations that are specific to nano-sized structures, as has been discussed in this review. Taking advantage of the special properties of nanomaterials for the identification and treatment of viral particles would serve to provide rapid relief from disease. 


\section{Conflicts of interest}

The authors declare no competing financial interest.

\section{Acknowledgements}

The authors would like to thank Jawaharlal Nehru University, New Delhi for providing infrastructure and research facilities. Sanjeev K. Jat would like to thank the DST-SERB Government of India for granting fellowship in the form of a national postdoc fellowship (PDF/2018/002524/LS). MKS acknowledges the funding support from SERB (ECR/2015/00495).

\section{References}

1 L. P. Kotra, in xPharm: The Comprehensive Pharmacology Reference, ed. S. J. Enna and D. B. Bylund, Elsevier, New York, 2007, pp. 1-2.

2 NIH Curriculum Supplement Series [Internet], National Institutes of Health (US), 2007.

3 A. Engering, L. Hogerwerf and J. Slingenbergh, Emerging Microbes Infect., 2013, 2, e5.

4 J. F. Lindahl and D. Grace, Infect. Ecol. Epidemiol., 2015, 5, 30048 .

5 L. Saker, K. Lee, B. Cannito, A. Gilmore and D. CampbellLendrum, Globalization and infectious diseases - a review of the linkages, 2004.

6 A. de Sherbinin, D. Carr, S. Cassels and L. Jiang, Annu. Rev. Environ. Resour., 2007, 32, 345-373.

7 C. Martin, P.-P. Pastoret, B. Brochier, M.-F. Humblet and C. Saegerman, Vet. Res., 2011, 42, 70.

8 J. Rosselló, M. Santana-Gallego and W. Awan, Health Pol. Plan., 2017, 32, 538-548.

9 A. J. McMichael, S. Friel, A. Nyong and C. Corvalan, $B M J$, 2008, 336, 191-194.

10 K. M. Smith, C. C. Machalaba, R. Seifman, Y. Feferholtz and W. B. Karesh, One Heal., 2019, 7, 100080.

11 L. A. Reperant and A. D. M. E. Osterhaus, Vaccine, 2017, 35, 4470-4474.

12 A. Iannello, O. Debbeche, E. Martin, L. H. Attalah, S. Samarani and A. Ahmad, J. Leukocyte Biol., 2006, 79, 16-35.

13 M. E. Craft, Philos. Trans. R. Soc., B, 2015, 370, 20140107.

14 H. Kruse, A.-M. Kirkemo and K. Handeland, Emerging Infect. Dis., 2004, 10, 2067-2072.

15 D. E. Bloom and D. Cadarette, Front. Immunol., 2019, 10, 549.

16 R. Zarychanski, T. L. Stuart, A. Kumar, S. Doucette, L. Elliott, J. Kettner and F. Plummer, Can. Med. Assoc. J., 2010, 182, 257-264.

17 E. C. Claas, A. D. Osterhaus, R. van Beek, J. C. De Jong, G. F. Rimmelzwaan, D. A. Senne, S. Krauss, K. F. Shortridge and R. G. Webster, Lancet, 1998, 351, 472-477.

18 N. Ramadan and H. Shaib, Germs, 2019, 9, 35-42.

19 L. R. Petersen, D. J. Jamieson, A. M. Powers and M. A. Honein, N. Engl. J. Med., 2016, 374, 1552-1563.
20 J. S. M. Peiris, Y. Guan and K. Y. Yuen, Nat. Med., 2004, 10, S88-S97.

21 G. L. Campbell, A. A. Marfin, R. S. Lanciotti and D. J. Gubler, Lancet Infect. Dis., 2002, 2, 519-529.

22 H. Meyer, M. Perrichot, M. Stemmler, P. Emmerich, H. Schmitz, F. Varaine, R. Shungu, F. Tshioko and P. Formenty, J. Clin. Microbiol., 2002, 40, 2919-2921.

23 Z. Bi, P. B. H. Formenty and C. E. Roth, J. Infect. Dev. Countries, 2008, 2, 3-23.

24 B. S. P. Ang, T. C. C. Lim and L. Wang, J. Clin. Microbiol., 2018, 56, e01875-e01877.

25 S. A. Meo, A. M. Alhowikan, T. Al-Khlaiwi, I. M. Meo, D. M. Halepoto, M. Iqbal, A. M. Usmani, W. Hajjar and N. Ahmed, Eur. Rev. Med. Pharmacol. Sci., 2020, 24, 2012-2019.

26 C.-C. Lai, T.-P. Shih, W.-C. Ko, H.-J. Tang and P.-R. Hsueh, Int. J. Antimicrob. Agents, 2020, 55, 105924.

27 E. Thomas, M. Yoneda and E. R. Schiff, Cold Spring Harbor Perspect. Med., 2015, 5, a021345.

28 C. Lewden, Int. J. Epidemiol., 2004, 34, 121-130.

29 C. Peteranderl, S. Herold and C. Schmoldt, Semin. Respir. Crit. Care Med., 2016, 37, 487-500.

30 S. Rampersad and P. Tennant, Viruses, 2018, 55-82.

31 M. Schmid, T. Speiseder, T. Dobner and R. A. Gonzalez, J. Virol., 2014, 88, 1404-1420.

32 D. R. Peaper and M. L. Landry, Handb. Clin. Neurol., 2014, 123, 123-147.

33 G. A. Storch, Clin. Infect. Dis., 2000, 31, 739-751.

34 R. H. Sedlak and K. R. Jerome, Diagn. Microbiol. Infect. Dis., 2013, 75, 1-4.

35 M. W. Taylor, Viruses and Man: A History of Interactions, Springer International Publishing, Cham, 2014, pp. 355-377.

36 G. A. Tannock, H. Kim and L. Xue, J. Med. Virol., 2020, 92, 129-138.

37 B. Greenwood, Philos. Trans. R. Soc., B, 2014, 369, 20130433.

38 R. Vardanyan and V. Hruby, Synthesis of Best-Seller Drugs, 2016, pp. 687-736.

39 G. K. Rout, H.-S. Shin, S. Gouda, S. Sahoo, G. Das, L. F. Fraceto and J. K. Patra, Artif. Cells, Nanomed., Biotechnol., 2018, 46, 1053-1062.

40 N. Zahin, R. Anwar, D. Tewari, M. T. Kabir, A. Sajid, B. Mathew, M. S. Uddin, L. Aleya and M. M. Abdel-Daim, Environ. Sci. Pollut. Res., 2020, 27, 19151-19168.

41 S. E. McNeil, in Methods in molecular biology, ed. S. E. McNeil, Humana Press, Totowa, NJ, 2011, vol. 697, pp. 3-8.

42 R. R. Arvizo, O. R. Miranda, M. A. Thompson, C. M. Pabelick, R. Bhattacharya, J. David Robertson, V. M. Rotello, Y. S. Prakash and P. Mukherjee, Nano Lett., 2010, 10, 2543-2548.

43 X. Cheng, G. Chen and W. R. Rodriguez, Anal. Bioanal. Chem., 2009, 393, 487-501.

44 C. Colino, C. Millán and J. Lanao, Int. J. Mol. Sci., 2018, 19, 1627.

45 J. Zhou, N. Krishnan, Y. Jiang, R. H. Fang and L. Zhang, Nano Today, 2021, 36, 101031.

46 A. S. Teja and P.-Y. Koh, Prog. Cryst. Growth Charact. Mater., 2009, 55, 22-45. 
47 A. Akbarzadeh, M. Samiei and S. Davaran, Nanoscale Res. Lett., 2012, 7, 144.

48 S. Gul, S. B. Khan, I. U. Rehman, M. A. Khan and M. I. Khan, Front. Mater., 2019, 6, 179.

49 B. Issa and I. M. Obaidat, Magnetic Resonance Imaging, IntechOpen, 2019.

50 S. K. Jat and R. R. Bhattacharjee, Colloids Surf., A, 2017, 529, 160-168.

51 J. Ruan, J. Ji, H. Song, Q. Qian, K. Wang, C. Wang and D. Cui, Nanoscale Res. Lett., 2012, 7, 309.

52 T. A. P. Rocha-Santos, TrAC, Trends Anal. Chem., 2014, 62, 28-36.

53 R. Kumar, M. Nayak, G. C. Sahoo, K. Pandey, M. C. Sarkar, Y. Ansari, V. N. R. Das, R. K. Topno, Bhawna, M. Madhukar and P. Das, J. Infect. Chemother., 2019, 25, 325-329.

54 J. M. Perez, F. J. Simeone, Y. Saeki, L. Josephson and R. Weissleder, J. Am. Chem. Soc., 2003, 125, 10192-10193.

55 V. Wurcel, A. Cicchetti, L. Garrison, M. M. A. Kip, H. Koffijberg, A. Kolbe, M. M. G. Leeflang, T. Merlin, J. Mestre-Ferrandiz, W. Oortwijn, C. Oosterwijk, S. Tunis and B. Zamora, Public Health Genomics, 2019, 22, 8-15.

56 P. D. Burbelo, M. J. Iadarola and A. Chaturvedi, Future Virol., 2019, 14, 39-49.

57 S. Khizar, N. M. Ahmad, N. Zine, N. Jaffrezic-Renault, A. Errachid-el-salhi and A. Elaissari, ACS Appl. Nano Mater., 2021, 4, 4284-4306.

58 H. Shao, C. Min, D. Issadore, M. Liong, T.-J. Yoon, R. Weissleder and H. Lee, Theranostics, 2012, 2, 55-65.

59 C. Duran, P. S. Sobieszczyk and F. J. Rybicki, Vascular Medicine: A Companion to Braunwald's Heart Disease, Elsevier, 2nd edn, 2013, pp. 166-183.

60 X. Li, X.-N. Zhang, X.-D. Li and J. Chang, Cancer Biol. Med., 2016, 13, 339-348.

61 H. Shao, T.-J. Yoon, M. Liong, R. Weissleder and H. Lee, Beilstein J. Nanotechnol., 2010, 1, 142-154.

62 W. Wang, P. Ma, H. Dong, H.-J. Krause, Y. Zhang, D. Willbold, A. Offenhaeusser and Z. Gu, Biosens. Bioelectron., 2016, 80, 661-665.

63 L. Shen, J. Zhou, Y. Wang, N. Kang, X. Ke, S. Bi and L. Ren, Small, 2015, 11, 1190-1196.

64 T. Shelby, T. Banerjee, I. Zegar and S. Santra, Sci. Rep., 2017, 7, 7377.

65 N. Younes, D. W. Al-Sadeq, H. Al-Jighefee, S. Younes, O. AlJamal, H. I. Daas, H. M. Yassine and G. K. Nasrallah, Viruses, 2020, 12, 582.

66 P. Oberacker, P. Stepper, D. M. Bond, S. Höhn, J. Focken, V. Meyer, L. Schelle, V. J. Sugrue, G.-J. Jeunen, T. Moser, S. R. Hore, F. von Meyenn, K. Hipp, T. A. Hore and T. P. Jurkowski, PLoS Biol., 2019, 17, e3000107.

67 C. Ma, C. Li, F. Wang, N. Ma, X. Li, Z. Li, Y. Deng, Z. Wang, Z. Xi, Y. Tang and N. He, J. Biomed. Nanotechnol., 2013, 9, 703-709.

68 W. K. Roth, Transfus. Med. Hemother., 2019, 46, 67-75.

69 C. Tang, Z. He, H. Liu, Y. Xu, H. Huang, G. Yang, Z. Xiao, S. Li, H. Liu, Y. Deng, Z. Chen, H. Chen and N. He, J. Nanobiotechnol., 2020, 18, 62.
70 S.-C. Lin, B. D. Carey, V. Callahan, J.-H. Lee, N. Bracci, A. Patnaik, A. K. Smith, A. Narayanan, B. Lepene and K. Kehn-Hall, PLoS One, 2020, 15, e0227058.

71 Z. Ali, J. Wang, Y. Tang, B. Liu, N. He and Z. Li, Biomater. Sci., 2017, 5, 57-66.

72 P. Michalek, S. Dostalova, H. Buchtelova, N. Cernei, L. Krejcova, D. Hynek, V. Milosavljevic, A. M. J. Jimenez, P. Kopel, Z. Heger and V. Adam, Electrophoresis, 2016, 37, 2025-2035.

73 Z. Zhao, H. Cui, W. Song, X. Ru, W. Zhou and X. Yu, bioRxiv, 2020, DOI: 10.1101/2020.02.22.961268.

74 M. G. Barbu, C. E. Condrat, D. C. Thompson, O. L. Bugnar, D. Cretoiu, O. D. Toader, N. Suciu and S. C. Voinea, Front. Cell Dev. Biol., 2020, 8, 143.

75 I. Gessner, J. W. U. Fries, V. Brune and S. Mathur, J. Mater. Chem. B, 2021, 9, 9-22.

76 J. Fernandez, F. Gharahdaghi and S. M. Mische, Electrophoresis, 1998, 19, 1036-1045.

77 S. Payne, Viruses, 2017, 37-52.

78 T.-C. Chou, W. Hsu, C.-H. Wang, Y.-J. Chen and J.-M. Fang, J. Nanobiotechnol., 2011, 9, 52.

79 R. M. Lequin, Clin. Chem., 2005, 51, 2415-2418.

80 G. N. Konstantinou, in Methods in Molecular Biology, ed. J. Lin and M. Alcocer, Springer New York, New York, NY, 2017, vol. 1592, pp. 79-94.

81 S. Nourani, H. Ghourchian and S. M. Boutorabi, Anal. Biochem., 2013, 441, 1-7.

82 D. Duan, K. Fan, D. Zhang, S. Tan, M. Liang, Y. Liu, J. Zhang, P. Zhang, W. Liu, X. Qiu, G. P. Kobinger, G. F. Gao and X. Yan, Biosens. Bioelectron., 2015, 74, 134-141.

83 L. Y. Hung, F. Y. Cheng, C. C. Huang, Y. C. Tsai, C. S. Yeh, H. Y. Lei and G. B. Lee, 2012 7th IEEE International Conference on Nano/Micro Engineered and Molecular Systems, NEMS 2012, IEEE, 2012, pp. 200-203.

84 S. Oh, J. Kim, V. T. Tran, D. K. Lee, S. R. Ahmed, J. C. Hong, J. Lee, E. Y. Park and J. Lee, ACS Appl. Mater. Interfaces, 2018, 10, 12534-12543.

85 M. L. Protopapa, Appl. Opt., 2009, 48, 778.

86 A. Reza, A. S. M. Noor and M. Maarof, Plasmonics Principles and Applications, InTech, 2012.

87 X. F. Zhang, Z. G. Liu, W. Shen and S. Gurunathan, Int. J. Mol. Sci., 2016, 17, 1534.

88 S. Sabouri, H. Ghourchian, M. Shourian and M. Boutorabi, Anal. Methods, 2014, 6, 5059-5066.

89 H. Malekzad, P. S. Zangabad, H. Mirshekari, M. Karimi and M. R. Hamblin, Nanotechnol. Rev., 2017, 6, 301-329.

90 R. R. Jones, D. C. Hooper, L. Zhang, D. Wolverson and V. K. Valev, Nanoscale Res. Lett., 2019, 14, 231.

91 H. Chen, A. Das, L. Bi, N. Choi, J.-I. Moon, Y. Wu, S. Park and J. Choo, Nanoscale, 2020, 12, 21560-21570.

92 N. Maccaferri, I. Zubritskaya, I. Razdolski, I.-A. Chioar, V. Belotelov, V. Kapaklis, P. M. Oppeneer and A. Dmitriev, J. Appl. Phys., 2020, 127, 080903.

93 A. K. Sarychev, A. Ivanov, A. Lagarkov and G. Barbillon, Materials, 2018, 12, 103. 
94 A. M. Shrivastav, U. Cvelbar and I. Abdulhalim, Commun. Biol., 2021, 4, 70.

95 V. I. Kukushkin, N. M. Ivanov, A. A. Novoseltseva, A. S. Gambaryan, I. V. Yaminsky, A. M. Kopylov and E. G. Zavyalova, PLoS One, 2019, 14, e0216247.

96 R. Wacker, B. Ceyhan, P. Alhorn, D. Schueler, C. Lang and C. M. Niemeyer, Biochem. Biophys. Res. Commun., 2007, 357, 391-396.

97 M. A. Tuan and N. H. Hai, J. Phys.: Conf. Ser., 2009, 187, 012059.

98 S. Y. Yang, W. C. Wang, C. B. Lan, C. H. Chen, J. J. Chieh, H. E. Horng, C.-Y. Hong, H. C. Yang, C. P. Tsai, C. Y. Yang, I. C. Cheng and W. C. Chung, J. Virol. Methods, 2010, 164, 14-18.

99 D. A. C. Thomson, K. Dimitrov and M. A. Cooper, Analyst, 2011, 136, 1599.

100 Y. F. Ran, C. Fields, J. Muzard, V. Liauchuk, M. Carr, W. Hall and G. U. Lee, Analyst, 2014, 139, 6126-6134.

101 H.-W. Chen, Z.-S. Fang, Y.-T. Chen, Y.-I. Chen, B.-Y. Yao, J.-Y. Cheng, C.-Y. Chien, Y.-C. Chang and C.-M. J. Hu, ACS Appl. Mater. Interfaces, 2017, 9, 39953-39961.

102 B. Tian, X. Liao, P. Svedlindh, M. Strömberg and E. Wetterskog, ACS Sens., 2018, 3, 1093-1101.

103 F. Zhang, L. Luo, H. Gong, C. Chen and C. Cai, RSC Adv., 2018, 8, 32262-32268.

104 J. Zhong, E. L. Rösch, T. Viereck, M. Schilling and F. Ludwig, ACS Sens., 2021, 6, 976-984.

105 H. Markides, M. Rotherham and A. J. El Haj, J. Nanomater., 2012, 2012, 1-11.

106 L. Bromberg, S. Raduyk and T. A. Hatton, Anal. Chem., 2009, 81, 5637-5645.

107 L. Bromberg, E. P. Chang, T. A. Hatton, A. Concheiro, B. Magariños and C. Alvarez-Lorenzo, Langmuir, 2011, 27, 420-429.

108 L. Bromberg, D. J. Bromberg, T. A. Hatton, I. Bandín, A. Concheiro and C. Alvarez-Lorenzo, Langmuir, 2012, 28, 4548-4558.

109 S. R. Kumar, M. Paulpandi, M. ManivelRaja, D. Mangalaraj, C. Viswanathan, S. Kannan and N. Ponpandian, RSC Adv., 2014, 4, 13409.

110 R. Zhang, K. Fan and X. Yan, Sci. China: Life Sci., 2020, 63, 1183-1200.

111 B. Liu and J. Liu, Nano Res., 2017, 10, 1125-1148.

112 Y. Zhou, B. Liu, R. Yang and J. Liu, Bioconjugate Chem., 2017, 28, 2903-2909.

113 L. Gao, K. Fan and X. Yan, Theranostics, 2017, 7, 3207-3227.

114 L. Gao, J. Zhuang, L. Nie, J. Zhang, Y. Zhang, N. Gu, T. Wang, J. Feng, D. Yang, S. Perrett and X. Yan, Nat. Nanotechnol., 2007, 2, 577-583.

115 T. Qin, R. Ma, Y. Yin, X. Miao, S. Chen, K. Fan, J. Xi, Q. Liu, Y. Gu, Y. Yin, J. Hu, X. Liu, D. Peng and L. Gao, Theranostics, 2019, 9, 6920-6935.

116 Y. Abo-zeid, N. S. M. Ismail, G. R. McLean and N. M. Hamdy, Eur. J. Pharm. Sci., 2020, 153, 105465.

117 J. K. Patra, G. Das, L. F. Fraceto, E. V. R. Campos, M. del, P. Rodriguez-Torres, L. S. Acosta-Torres, L. A. Diaz-Torres,
R. Grillo, M. K. Swamy, S. Sharma, S. Habtemariam and H.S. Shin, J. Nanobiotechnol., 2018, 16, 71.

118 S. K. Jat, D. Selvaraj, R. Muthiah and R. R. Bhattacharjee, ChemistrySelect, 2018, 3, 13123-13131.

119 J. Varshosaz, World J. Gastroenterol., 2015, 21, 12022.

120 S.-R. Ryoo, H. Jang, K.-S. Kim, B. Lee, K. B. Kim, Y.-K. Kim, W.-S. Yeo, Y. Lee, D.-E. Kim and D.-H. Min, Biomaterials, 2012, 33, 2754-2761.

121 R. Jayant, V. Atluri, M. Agudelo, V. Sagar, A. Kaushik and M. Nair, Int. J. Nanomed., 2015, 1077.

122 R. K. Upadhyay, BioMed Res. Int., 2014, 1-37.

123 M. Masserini, ISRN Biochem., 2013, 1-18.

124 L. Fiandra, M. Colombo, S. Mazzucchelli, M. Truffi, B. Santini, R. Allevi, M. Nebuloni, A. Capetti, G. Rizzardini, D. Prosperi and F. Corsi, Nanomedicine, 2015, 11, 1387-1397.

125 B. Issa, I. Obaidat, B. Albiss and Y. Haik, Int. J. Mol. Sci., 2013, 14, 21266-21305.

126 A. Chicheł, J. Skowronek, M. Kubaszewska and M. Kanikowski, Rep. Pract. Oncol. Radiother., 2007, 12, 267-275.

127 I. M. Obaidat, V. Narayanaswamy, S. Alaabed, S. Sambasivam and C. V. V. Muralee Gopi, Magnetochemistry, 2019, 5, 67.

128 J. P. Williams, P. Southern, A. Lissina, H. C. Christian, A. K. Sewell, R. Phillips, Q. Pankhurst and J. Frater, Int. J. Nanomed., 2013, 8, 2543-2554.

129 M. Aminul Islam and M. Ziaul Ahsan, Am. J. Nanosci., 2020, 6, 18.

130 A. Ojha, Waterborne Pathogens, Elsevier, 2020, pp. 385-432.

131 O. A. Sadik, N. Du, I. Yazgan and V. Okello, Nanotechnology Applications for Clean Water: Solutions for Improving Water Quality, Elsevier, 2nd edn, 2014, pp. 95-108.

132 K. Kalantari, E. Mostafavi, A. M. Afifi, Z. Izadiyan, H. Jahangirian, R. Rafiee-Moghaddam and T. J. Webster, Nanoscale, 2020, 12, 2268-2291.

133 H. Bahadar, F. Maqbool, K. Niaz and M. Abdollahi, Iran. Biomed. J., 2016, 20, 1-11.

134 I. Pujalté, I. Passagne, B. Brouillaud, M. Tréguer, E. Durand, C. Ohayon-Courtès and B. L'Azou, Part. Fibre Toxicol., 2011, 8, 10.

135 S. Park, H. H. Park, S. Y. Kim, S. J. Kim, K. Woo and G. Ko, Appl. Environ. Microbiol., 2014, 80, 2343-2350.

136 H. H. Park, S. Park, G. Ko and K. Woo, J. Mater. Chem. B, 2013, 1, 2701-2709.

137 J.-A. Park, S.-B. Kim, C.-G. Lee, S.-H. Lee and J.-W. Choi, J. Environ. Sci. Health, Part A: Toxic/Hazard. Subst. Environ. Eng., 2014, 49, 1116-1124.

138 N. Delaviz, P. Gill, A. Ajami and M. Aarabi, RSC Adv., 2015, 5, 79433-79439.

139 S. Zhan, Y. Yang, Z. Shen, J. Shan, Y. Li, S. Yang and D. Zhu, J. Hazard. Mater., 2014, 274, 115-123.

140 https://pib.gov.in/PressReleseDetailm.aspx?PRID=1617890, PIB, India, 2020, pp. 24-26.

141 N. Databases, N. Catalog and N. Jobs, Nor. Univ. Sci. Technol., 2020, pp. 1-10.

142 https:/www.t2biosystems.com/products-technology/t2sarscov-2-panel/. 
143 S. R. Ahmed, S. W. Kang, S. Oh, J. Lee and S. Neethirajan, Heliyon, 2018, 4, e00766.

144 D. W. Coyne, Expert Opin. Pharmacother., 2009, 10, 2563-2568.

145 G. K. Kouassi and J. Irudayaraj, Anal. Chem., 2006, 78, 3234-3241.

146 T. Tanaka, R. Sakai, R. Kobayashi, K. Hatakeyama and T. Matsunaga, Langmuir, 2009, 25, 2956-2961.

147 M. Pita, J. M. Abad, C. Vaz-Dominguez, C. Briones, E. Mateo-Martí, J. A. Martín-Gago, M. del Puerto Morales and V. M. Fernández, J. Colloid Interface Sci., 2008, 321, 484-492.

148 K. Li, Y. Lai, W. Zhang and L. Jin, Talanta, 2011, 84, 607-613.

149 S. Li, H. Liu and N. He, J. Nanosci. Nanotechnol., 2010, 10, 4875-4882.

150 I. Willner, Z. Cheglakov, Y. Weizmann and E. Sharon, Analyst, 2008, 133, 923.

151 K. Kang, J. Choi, J. H. Nam, S. C. Lee, K. J. Kim, S.-W. Lee and J. H. Chang, J. Phys. Chem. B, 2009, 113, 536-543.

152 T. T. Hien Pham, C. Cao and S. J. Sim, J. Magn. Magn. Mater., 2008, 320, 2049-2055.
153 Z. Ma, Y. Guan and H. Liu, J. Magn. Magn. Mater., 2006, 301, 469-477.

154 Y. Liu, S. Jia, Q. Wu, J. Ran, W. Zhang and S. Wu, Catal. Commun., 2011, 12, 717-720.

155 G. Bayramoğlu, S. Kiralp, M. Yilmaz, L. Toppare and M. Y. Arıca, Biochem. Eng. J., 2008, 38, 180-188.

156 K. Moriyama, K. Sung, M. Goto and N. Kamiya, J. Biosci. Bioeng., 2011, 111, 650-653.

157 B. Sahoo, S. K. Sahu and P. Pramanik, J. Mol. Catal. B: Enzym., 2011, 69, 95-102.

158 G. Y. Li, K. L. Huang, Y. R. Jiang, D. L. Yang and P. Ding, Int. J. Biol. Macromol., 2008, 42, 405-412.

159 Y. Li, X. Xu, C. Deng, P. Yang and X. Zhang, J. Proteome Res., 2007, 6, 3849-3855.

160 H. Kempe and M. Kempe, Biomaterials, 2010, 31, 9499-9510.

161 W. Yu-Hong, C. Rui and L. Ding, Nanoscale Res. Lett., 2011, 6, 461 .

162 T. L. Kamikawa, M. G. Mikolajczyk, M. Kennedy, P. Zhang, W. Wang, D. E. Scott and E. C. Alocilja, Biosens. Bioelectron., 2010, 26, 1346-1352. 